OPEN ACCESS

Edited by:

Federico Giove

Centro Fermi-Museo Storico della

Fisica e Centro Studi e Ricerche

Enrico Fermi, Italy

Reviewed by:

Michael D. Noseworthy,

McMaster University, Canada

Silvia Capuani

National Research Council (CNR), Italy

*Correspondence:

Allegra Conti

allegra.conti@uniroma2.it

Specialty section:

This article was submitted to Medical Physics and Imaging,

a section of the journal

Frontiers in Physics

Received: 31 March 2020

Accepted: 12 August 2020

Published: 30 September 2020

Citation:

Conti A, Kamimura HAS, Novell A,

Duggento A and Toschi N (2020)

Magnetic Resonance Methods for

Focused Ultrasound-Induced

Blood-Brain Barrier Opening.

Front. Phys. 8:547674.

doi: 10.3389/fphy.2020.547674

\section{Magnetic Resonance Methods for Focused Ultrasound-Induced Blood-Brain Barrier Opening}

\author{
Allegra Conti ${ }^{1 *}$, Hermes A. S. Kamimura ${ }^{2}$, Anthony Novell ${ }^{3}$, Andrea Duggento ${ }^{1}$ and \\ Nicola Toschi ${ }^{1,4}$ \\ ${ }^{1}$ Department of Biomedicine and Prevention, University of Rome Tor Vergata, Rome, Italy, ${ }^{2}$ Department of Biomedical \\ Engineering, Columbia University, New York, NY, United States, ${ }^{3}$ Université Paris-Saclay, CEA, CNRS, Inserm, BioMaps, \\ Orsay, France, ${ }^{4}$ Athinoula A. Martinos Center for Biomedical Imaging, Harvard Medical School, Charlestown, MA, \\ United States
}

Since its discovery in 2001, the interest in the low-intensity focused ultrasound (FUS)-mediated blood-brain barrier (BBB) disruption to deliver genes and drugs to brain tissue has increased steadily. Increasingly sophisticated sonication protocols and dedicated hardware are being developed to efficiently and safely permeabilize the BBB, and novel magnetic resonance (MR)-based technologies have been designed to guide FUS-induced BBB opening protocols. MR imaging (MRI) allows not only to more precisely target brain regions and evaluate the outcome of sonication in terms of enhanced BBB permeability but also to control the effects of ultrasound on brain structure and function. This review summarizes the state of the art in current MRI hardware and methods used in BBB opening protocols both in pre-clinical and clinical settings.

Keywords: focused ultrasound, magnetic resonance imaging, blood-brain barrier, therapeutic ultrasound, drug delivery system

\section{INTRODUCTION}

The blood-brain barrier (BBB) is a semipermeable structure of the central nervous system (CNS) that controls passive diffusion and active transport of solutes and nutrients between the blood and brain compartments. While this structure is essential for brain homeostasis, it often prevents drug molecules and other substances from reaching therapeutic concentrations in the brain. Low intensity focused ultrasound (LIFUS) in conjunction with intravenously injected gas-encasing microbubbles (MBs) can reversibly disrupt the $\mathrm{BBB}$, hence enabling greatly enhanced drug delivery in the brain [1-4]. In comparison to other techniques which result in diffuse BBB breakdown (e.g., mannitol administration) and hence widespread CNS uptake with potential off-target effects [5], FUS application induces targeted BBB disruption and local drugs release. Briefly, focused ultrasound (US) transducers transmit acoustic waves that converge in a millimeter-sized focal spot (FS) (Figure 1A) [1, 6]. Microbubbles circulating through capillaries and vessels within the FS region oscillate and interact with the tissue [7]. During this phenomenon (called cavitation), microbubbles expand toward the capillaries and small vessels wall, loosening the tight junctions of endothelial cells and creating gaps between these cells. Particles of interest exploit these gaps to can cross from the bloodstream to the brain $[8,9]$ (Figure 1B). LIFUS-mediated BBB disruption has been widely demonstrated in animal models $[7,10-14]$, and it has been tested in clinical settings for the treatment of neurodegenerative diseases such as Alzheimer's and Parkinson's Disease [15-17]. The same kind of approach has also been demonstrated, capable of disrupting the blood-tumor 


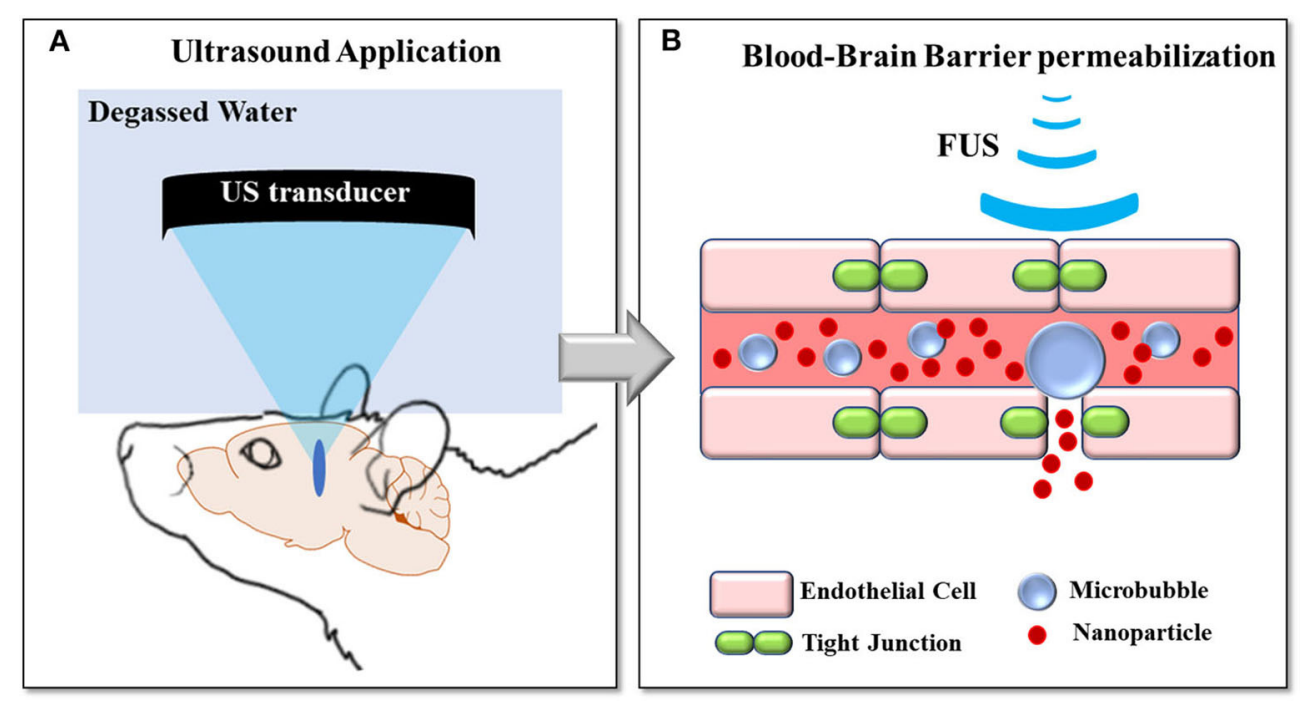

FIGURE 1 | FUS-induced BBB opening concepts: (A) Ultrasound pressure waves are converged in a millimeter-sized FS thanks to a transducer coupled to the head via a balloon filled with water. (B) Microbubbles circulating through the bloodstream cavitate within the FS region, loosening the tight junctions of endothelial cells and creating gaps between these cells.

barrier (BTB) and the intact BBB within tumor-infiltrated healthy tissue. This allowed releasing otherwise unattainable concentrations of therapeutics [18-20].

LIFUS-induced BBB disruption protocols are often conducted under magnetic resonance imaging (MRI) guidance, not only for more precise targeting of the brain [8] but also to evaluate $\mathrm{BBB}$ opening and closure. This includes the potential use of magnetic resonance (MR) contrast agents (CA) [11, 14, 21, 22] to control the safety of the permeabilization protocol $[23,24]$, as well as putative changes induced in brain function [25-27].

Abbreviations: ALS, Amyotrophic Lateral Sclerosis; AP, Acoustic Pressure; BBB, Blood-Brain Barrier; BOLD, blood oxygenation level-dependent; CA, Contrast Agent; (CA)-maps, concentration maps; CE, contrast-enhanced; CNS, Central Nervous System; DC, Duty Cycle; DCE, dynamic contrast enhancement; EEG, Electroencephalography; EES, Extravascular-extracellular space; EPI, Echo-Planar Imaging; FA, Flip Angle; FFE, fast field echo; FGE, fast gradient echo; FLASH, fast low angle shot; FOV, Field Of View; FS, focal spot; FUS, Focused Ultrasound; fMRI, functional Magnetic Resonance Imaging; GABA, gammaaminobutyric acid; GBM, Glioblastoma; Gd-BOPTA, Gadobenate disodium; Gd-DO3A-butriol, Gadobutrol; Gd-DOTA, Gadoterate meglumine; Gd-DTPA, Gadolinium-diethylene-triamine pentaacetic acid; Gd-DTPA-BMA, Gadolinium-diethylene-triamine pentaacetic acid- bis-methylamide; GKM, general kinetic model; GLUT 1, glucose transporter 1; HRF, hemodynamic response function; IC, inertial cavitation; IR-FGE, inversion recovery fast gradient echo; IR-FSPGR, inversion recovery prepared fast spoiled gradient echo; IVIM, intravoxel incoherent motion; LIFUS, low intensity focused ultrasound; MBs, microbubbles; MI, mechanical index; MR, Magnetic Resonance; MR-ARFI, magnetic resonance acoustic radiation force imaging; MRE, Magnetic Resonance elastography; MRI, Magnetic Resonance Imaging; R1, longitudinal relaxation rate; PL, pulse length; RF, radiofrequency; SE, Spin-Echo; S1HL, right primary somatosensory cortex hindlimb region; SNAP, Simultaneous Non-contrast Angiography and intraPlaque hemorrhage; SNR, signal to noise ratio; SSEP, somatosensory evoked potential; SW, susceptibility weighted; $\mathrm{t} 1 / 2$, half closure time; TE, echo time; TR, repetition time; t-MRE, Transient MR elastography; SPIO, superparamagnetic iron oxide; UCA, ultrasound contrast agents; US, Ultrasound.
This review summarizes the state of the art in MRI sequences and methods used in BBB opening protocols, both in pre-clinical and clinical settings. First, we describe MRI-compatible US systems used during permeabilization under MR-guidance. Then, we introduce MRI sequences used in different sonication protocols suitable for targeting and monitoring BBB permeabilization and closure dynamics. Given that, under certain acoustic conditions, LIFUS-mediated BBB disruption may induce concomitant effects on brain microstructure and function, we also focus on MRI methods used to investigate such changes after FUS exposure.

\section{MR COMPATIBLE LIFUS SYSTEMS}

Over the last 15 years, MR compatible US systems have been developed for both pre-clinical and clinical applications. In 2015, Magnin et al. [28] presented a new MR-guided motorized FUS system able to move a US transducer (diameter $25 \mathrm{~mm}$, focal depth $20 \mathrm{~mm}, 1.5 \mathrm{MHz}$ ) for small animal experiments within 7T MRI pre-clinical scanners. Thanks to the coupling of this system with real-time transfer and reconstruction of MRI images, this device can precisely deliver submicrometer and micrometer particles within rat and mouse brain to a single location or a volume by sonicating along arbitrary trajectories (see Figure 2). In 2018, Kamimura et al. [29] reported on a 7T-MRI compatible system suitable to guide BBB opening experiments in non-human primates (14-elements transducer, $7 \mathrm{~cm}$ diameter, $500 \mathrm{kHz}$ ). By monitoring microbubble cavitation in real-time, this system is capable of tuning the level of acoustic pressure on-line, hence avoiding inertial cavitation (IC), and in turn, damage to brain tissue.

In parallel with the first pre-clinical prototype (2004), which was tested in the rabbit brain and was based on 


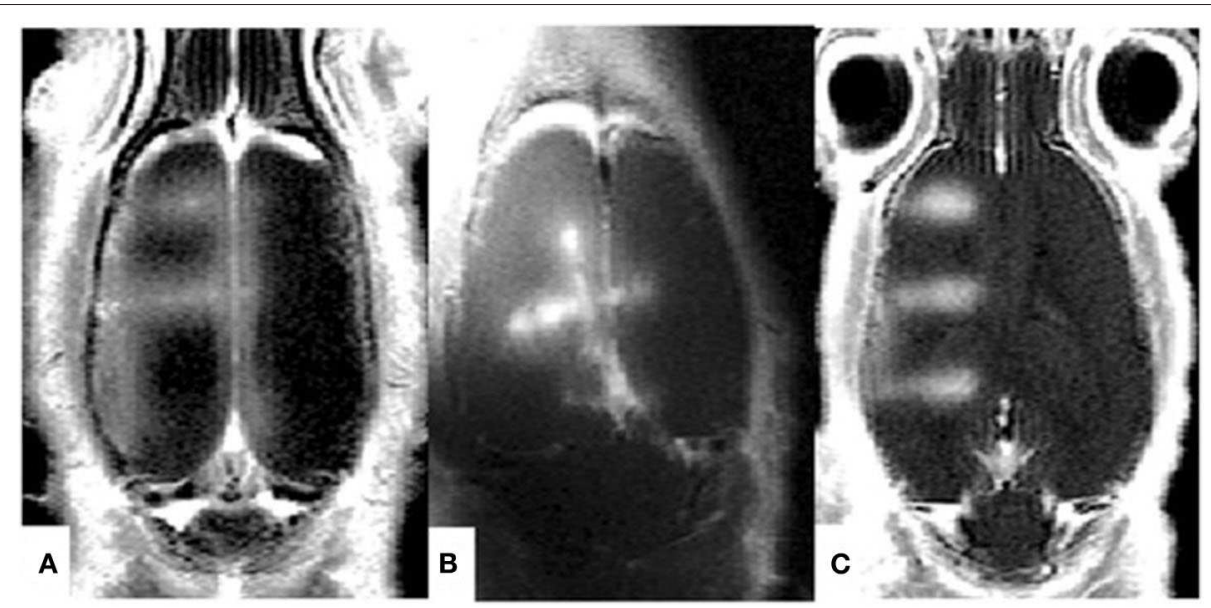

FIGURE 2 | Contrast Agent enhanced MRI images obtained after MRgFUS-induced BBB opening in rats. Thanks to the MRI guidance, BBB disruption has been performed along different trajectories [(A-C) in the figure]. Reproduced with permission from [28].

MRI-compatible phased array system optimized for transcranial FUS transmission, a clinical MR-compatible FUS system has also been developed [30]. This hemispherical 500-element ultrasound phased array (diameter $30 \mathrm{~cm}$ ) operating at $700-800 \mathrm{kHz}$, was capable of reaching up to $1,080 \mathrm{~W}$ of local acoustic power. This device was then modified by INSIGHTEC (Haifa, Israel) to operate in a clinical context. INSIGHTEC's current product is the ExAblate 4000; a $30-\mathrm{cm}$ diameter hemispheric 1,024element phased array transducer operating at "low" $(200 \mathrm{kHz})$ and "high" $(650 \mathrm{kHz})$ frequencies [31]. This device can be integrated with MRI scanners operating both at $1.5 \mathrm{~T}$ and 3T. ExAblate 4000 is currently employed in several clinical trials to permeabilize the $\mathrm{BBB}$ in patients with Alzheimer disease [32] $]^{1,2,3}$, Glioblastoma (GBM) [17 $]^{4,5,6}$, Her2-positive Breast Cancer Brain Metastases ${ }^{7}$, Amyotrophic Lateral Sclerosis ${ }^{8}$

\footnotetext{
${ }^{1}$ ExAblate Blood-Brain Barrier Opening for Treatment of Alzheimer's Disease. Available online at: https://clinicaltrials.gov/ct2/show/NCT03739905 (accessed January 2, 2020).

${ }^{2}$ Blood-Brain-Barrier Opening Using Focused Ultrasound With IV Contrast Agents in Patients With Early Alzheimer's Disease. Available online at: https:// clinicaltrials.gov/ct2/show/NCT02986932 (accessed January 2, 2020).

${ }^{3}$ ExAblate Blood-Brain Barrier (BBB) Disruption for the Treatment of Alzheimer's Disease. Available online at: https://clinicaltrials.gov/ct2/show/NCT03671889 (accessed January 2, 2020).

${ }^{4}$ ExAblate Blood Brain Barrier Disruption (BBBD) for Planned Surgery in Suspected Infiltrating Glioma. Available online at: https://clinicaltrials.gov/ct2/ show/NCT03322813 (accessed January 2, 2020).

${ }^{5}$ ExAblate Blood-Brain Barrier Disruption for Glioblastoma in Patients Undergoing Standard Chemotherapy. Available online at: https://clinicaltrials. gov/ct2/show/NCT03712293 (accessed January 2, 2020).

${ }^{6}$ Assessment of Safety and Feasibility of ExAblate Blood-Brain Barrier (BBB) Disruption for Treatment of Glioma. Available online at: https://clinicaltrials.gov/ ct2/show/NCT03616860 (accessed January 2, 2020).

${ }^{7}$ Blood Brain Barrier Disruption (BBBD) Using MRgFUS in the Treatment of Her2-positive Breast Cancer Brain Metastases. Available online at: https:// clinicaltrials.gov/ct2/show/NCT03714243 (accessed January 2, 2020).

${ }^{8}$ Blood-Brain Barrier Opening Using MR-Guided Focused Ultrasound in Patients With Amyotrophic Lateral Sclerosis. Available online at: https://clinicaltrials.gov/ ct2/show/NCT03321487 (accessed January 2, 2020).
}

(ALS) as well as Parkinson's Disease Dementia ${ }^{9}$. In addition to INSIGHTEC, recently, CarThera (France) has developed a FUS system for permeabilizing the BBB in humans. In 2016, Goldwirt et al. [33] presented for the first time an MRI-compatible US system capable of enhancing drug concentration within the brain after BBB disruption. This device (named SonoCloud ${ }^{\circledR}$ ) is composed of an implantable, unfocused single-element ultrasound transducer based on a $10-\mathrm{mm}$ flat piezoceramic disk powered by an external generator ${ }^{10}$. After being tested on primates for toxicity and safety through MRI, PET, electroencephalography (EEG), somatosensory evoked potential (SSEP) monitoring, behavioral scales, and histopathological analysis [34], SonoCloud ${ }^{\circledR}$ has been used to disrupt the BBB and deliver high concentrations of carboplatin in mouse [35] and primate models [34]. The same system has also been used in a clinical trial to successfully release carboplatin in tumor areas of GBM patients [36]. Indeed, brain tumors in general and GBMs in particular, are characterized by heterogeneous vascularity: while internal regions of the tumor core have a compromised and more-permeable BBB (the BTB), the periphery of the tumor hosts a mainly intact BBB [37]. LIFUS application can, therefore, be useful to permeabilize the intact tumor vasculature, to further disrupt the already permeable BTB, and to increase the permeability in the peritumoral area where tumor seeds may be present.

Papers described in this section were the results of a PubMed search using the keywords MRI AND FUS AND BBB-opening, Carthera AND BBB-opening, and on Google Scholar search using the keywords exablate AND 4000-BBB-opening. Both searches were executed on 20/12/2019.

\footnotetext{
${ }^{9}$ A Study to Evaluate Temporary Blood Brain Barrier Disruption in Patients With Parkinson's Disease Dementia. Available online at: https://clinicaltrials.gov/ct2/ show/NCT03608553 (accessed January 2, 2020).

${ }^{10} \gg$ Device. Available at: https://carthera.eu/sono-cloud/device/ (accessed January 2, 2020).
} 


\section{MR IMAGING METHODS TO DETECT THE FUS BEAM IN THE BRAIN}

In 1995, MRI acquisitions were used for the first time to detect propagating ultrasound waves [38]. Muthupillai et al. [38] used MR elastography (MRE) to reveal submicrometer movements induced in vitro by transient shear waves, hence demonstrating the capability of this technique to estimate elastic properties of tissue along the direction of phase-locked magnetic field gradients. MRE techniques are suitable to detect both linear (such as the linear shear modulus) and non-linear elasticity parameters [39].

In 2008, Souchon et al. [40] proposed specific echo-planar imaging (EPI) MRE sequence called transient MR elastography (t-MRE), capable of estimating acoustic power from the phase shift of the MRE signal. This technique, which was tested on ex vivo tissue samples, allows to image transient shear waves generated by the ultrasonic radiation force.

In the same year, an additional method [magnetic resonance acoustic radiation force imaging (MR-ARFI)] capable of measuring focal tissue displacements caused by US was described by McDannold and Maier and tested in ex vivo tissue samples [41]. The authors used quasistatic MR elastography with a one-dimensional MRI pulse sequence triggered to be synchronous with the US frequency (1.63 or $1.5 \mathrm{MHz}$ ). More specifically, in the sequence proposed by McDannold et al. [41] the authors used two displacement-encoding gradients with opposite polarities, applied during a spin-echo (SE) sequence, between the $90^{\circ}$ and $180^{\circ} \mathrm{RF}$ pulses and between the $180^{\circ}$ radiofrequency $(\mathrm{RF})$ pulse and the signal readout. The US pulse is triggered by the first displacement-encoding gradient and is terminated after the end of the second gradient. Focal tissue displacements due to US are assumed to be proportional to the phase difference between signals acquired with opposite encoding polarities.

It was only in 2009 that motion-sensitized MRI sequences able to delineate the US focus in the brain were developed (see Figure 3A). Larrat et al. [42] presented a motionsensitized MR sequence optimized to detect brain tissue displacements at the US focus when the latter is as small as few micrometers. The technique consists of a standard multislice SE sequence with two additional bipolar sinusoidal gradients equally distant to the $180^{\circ} \mathrm{RF}$ pulse and synchronized with the ultrasound bursts.

While Larrat et al. [42] optimized the MR-ARFI sequence for use in animal experiments, in 2013, Kaye and Pauly improved this technique for in vivo applications in humans [43]. As a result, MR-ARFI provides satisfactory image quality even in the presence of subject motion. By starting from a SE MRI-ARFI, the authors showed a reduction of motion artifacts when bipolar encoding is repeated with an optimized duration. In particular, the MR-ARFI images obtained by Kayle and Pauly [43] show that a gradient duration of $12 \mathrm{~ms}$, combined with a US pulse duration of $19 \mathrm{~ms}$, result in an optimized displacement phase signal to noise ratio (SNR). Figure $3 \mathrm{~B}$ shows tissue displacements $\left(\Delta \phi_{d}\right)$ recorded by Kayle and Pauly in ex-vivo and in vivo acquisitions (first and second row, respectively) for different duration of encoding gradients, $\delta$.

In a recent paper by $\mathrm{Wu}$ et al. [44], a novel method based entirely on MR without the need for CA was introduced to monitor the targeted location of microbubble-enhanced FUS (and hence BBB disruption). The authors measured localized changes in gradient-echo MR signals due to microbubbles cavitation-induced perturbation of flow. This method was first validated in vitro by using flowing phantom experiments where microbubble concentrations of $0.1,0.25,0.5,0.75$, and $1 \%$ were infused while bursting FUS pulses with an acoustic pressure (AP) of 0.4 and $1 \mathrm{MPa}$. Successively, the same protocol was tested on rats by using an $\mathrm{AP}$ of $0.8 \mathrm{MPa}$ and a $0.25 \%$ microbubble concentration.

Papers described in this section were the result of a PubMed search using the keywords MRI AND FUS AND BBBopening, ARFI, AND BBB-opening. Searches were executed on $10 / 01 / 2019$.

\section{A Rat Brain} Magnitude Displacement phase

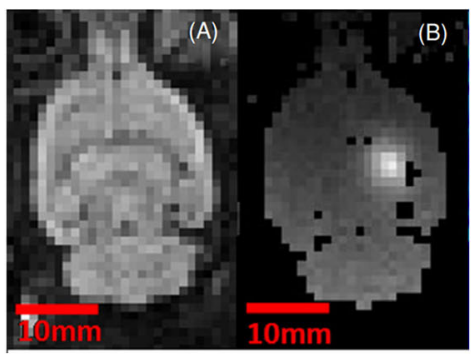

\section{B Human Brain}

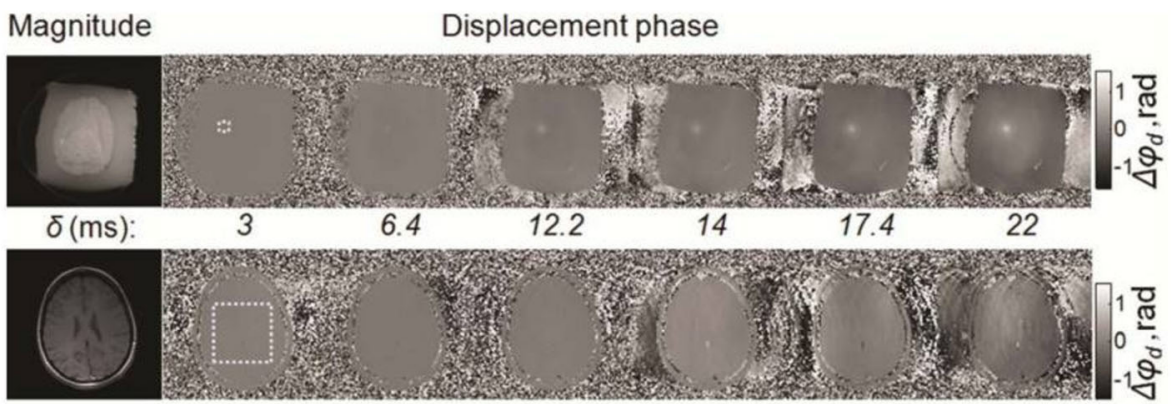

FIGURE 3 | (A) Magnitude (A) and phase image (B) obtained by [42] through and ARFI sequence. The bright spot in figure (B) represents the FUS focal spot. Figure adapted with permission from [42]. (B): in vitro (above) and in vivo (bottom) MR acoustic radiation force images of a human brain [43]. On the left and right part of the figure, magnitude and phase images are shown, respectively. Higher values of tissue displacements $\left(\Delta \phi_{d}\right)$ in phase images acquired for different duration of encoding gradients $(\delta)$ indicate FS location. Figure adapted with permission from [43]. 


\section{MRI ACQUISITIONS FOR BBB-OPENING EVALUATION}

BBB permeabilization facilitates the passage of particles smaller than $65 \mathrm{~nm}$ from the bloodstream to the brain $[14,21]$. Commercial MR contrast agents (MR-CAs) are typically sized around between 1 and $60 \mathrm{~nm}$ [14] and can, therefore, cross the permeabilized $\mathrm{BBB}$ and diffuse within brain tissue. Diffusing MRCAs are paramagnetic agents able to shorten the tissue relaxation times (T1 and, less frequently, T2), hence enhancing contrasts within MR-images. For this reason, to evaluate the degree of permeabilization obtained through different acoustic protocols, several groups administer (both in animals and humans), MRCAs right after US application.

The first study to report BBB disruption without damaging the surrounding parenchymal cells was published by Hynynen et al. [21]. The authors investigated the mechanisms of FUS-induced $\mathrm{BBB}$ opening in rabbits using brain MRI, including contrastenhanced imaging. These authors administrated an ultrasound contrast agent (UCA) (Optison ${ }^{\mathrm{TM}}$; Mallinckrodt Inc., St. Louis, $\mathrm{MO}$ ) before sonicating with different powers ranging from 0.2 to 11.5 W. In order to evaluate the BBB permeabilization after FUS application, MR-CAs (diethylene-triamine pentaacetic acid, GdDTPA, Magnevist ${ }^{\circledR}$; Berlex Laboratories, Wayne, NJ; molecular weight, $928 \mathrm{~d}$ ) were injected and imaged within the brain using gradient-echo (GE)-MRI acquisitions performed through a $1.5 \mathrm{~T}$ MRI scanner (GE Medical Systems) and a T1-weighted fast SE MRI sequence $[\mathrm{TR} / \mathrm{TE}=500 / 17 \mathrm{~ms}$; spatial resolution $(\mathrm{x}, \mathrm{y}$, $\mathrm{z})=400 \times 400 \times 1.5 \mathrm{~mm}]$. In this paper, sonications were conducted after craniotomy. In 2005, the same group employed the same MRI system to demonstrate that FUS at $690 \mathrm{kHz}$ and APs ranging within 0.4 and 1.2 MPa could safely open the BBB in rabbits through the intact skull [45]. Also, Choi et al. [46] demonstrated the feasibility of BBB opening through intact mice skulls, where images with a sub-millimeter resolution, acquired on a 9.4 T MRI scanner (Bruker Medical; Boston, MA), were able to localize the $\mathrm{BBB}$ opening area in the hippocampus also using an intravenously administered MR- T1 CA (diethylene-triamine pentaacetic acid-bis-methylamide, Gd DTPA-BMA, Omniscan ${ }^{\circledR}$; Amersham Health, AS Oslo, Norway), which was injected (10 $\mu \mathrm{L}$ ) into the right femoral vein $15 \mathrm{~min}$ before sonication. In this study, the authors adopted a transducer working at $1.5 \mathrm{MHz}$, with a 20\% Duty Cycle (DC) and APs ranging from 2.0 to 2.7 $\mathrm{MPa}$ (with an in-situ AP attenuated from the skull by 18\%). With a similar protocol, the same authors then demonstrated the efficacy of their permeabilization protocol in a mouse model even when a lower AP (e.g., 0.8 MPa) is used [47]. The MRI sequence used in this case was a T1-weighted SE $(\mathrm{TR} / \mathrm{TE}=246.1 / 10 \mathrm{~ms}$; matrix size: $256 \times 256$; FOV: $1.92 \times 1.92 \mathrm{~cm}$; slice thickness: $0.6 \mathrm{~mm})$.

In 2008, McDannold et al. [48] used MRI to study the effects of both acoustic parameters and UCA dose on FUSinduced $\mathrm{BBB}$ permeabilization in rabbit brains. The authors found no differences in $\mathrm{BBB}$ opening between UCA doses and US parameters while working at $0.69 \mathrm{MHz}$, with APs between 0.1 and $1.5 \mathrm{MPa}$ and using Optison with doses of 50, 100, $250 \mu \mathrm{L} / \mathrm{kg}$. This study employed a clinical $1.5 \mathrm{~T}$ MRI system
(GE Healthcare, Milwaukee, WI) and T1-weighted images after Magnevist ${ }^{\circledR}$ administration (Gd-DTPA, Berlex Laboratories, Inc.) (T1-weighted fast spin-echo MRI acquisition; TR/TE: 500/15 to $23 \mathrm{~ms}$; matrix size: $256 \times 256$; FOV: $10 \mathrm{~cm}$; slice thickness: $1.5 \mathrm{~mm}$; interslice spacing: $1.5 \mathrm{~mm}$ ).

Contrast-enhanced MRI has also been used to reveal targeting improvements achieved with different ultrasound pulse sequences. Short pulses were capable of reducing the BBB opening size by avoiding standing waves inside the brain caused by skull reflection [49]. Alternatively, coded excitation based on frequency modulation of ultrasound signals has proven capable of suppressing standing waves and increase targeting specificity $[50,51]$.

Thanks to the detection of inertial cavitation (IC) in the presence of Definity ${ }^{\circledR}$ (Lantheus Medical Imaging, N. Billerica, MA) microbubbles and the acquisition of T1-weighted MR images at 9.4 $\mathrm{T}$ following $\mathrm{BBB}$ permeabilization and injection of MR-CA (Omniscan, Amersham Health, Gd DTPA-BMA), Tung et al. [52] showed that $\mathrm{BBB}$ opening could be induced without any cellular damage at an AP of 0.30 and $0.45 \mathrm{MPa}$. The authors sonicated mice brains by using a US transducer working at $1.5 \mathrm{MHz}$, with a DC of $20 \%$ and pulse repetition frequency of $10 \mathrm{~Hz}$. They verified the validity of their permeabilization protocol by acquiring 3D T1-weighted Simultaneous Noncontrast Angiography and intraPlaque hemorrhage (SNAP) gradient echo pulse sequence $\left[\mathrm{TR} / \mathrm{TE}=20 / 4 \mathrm{~ms}, \mathrm{FA}=25^{\circ}\right.$, resolution $(\mathrm{x}, \mathrm{y}, \mathrm{z})=75 \times 75 \times 312.5 \mu^{3}$ ]. The same group has successively confirmed the safety of this acoustic protocol by using histological analysis [53].

In 2011, Marquet et al. [54] used the same range of acoustic pressures (between 0.3 and $0.6 \mathrm{MPa}$ ) to permeabilize the $\mathrm{BBB}$ in non-human primates successfully. In this study, T1-weighted MR images at $3 \mathrm{~T}$ were used to confirm $\mathrm{BBB}$ disruption by tracking the uptake of gadodiamide (Gd-DTPA) in the brain. The T1-weighted MRI sequence used to confirm BBB opening was a 3D Spoiled Gradient-Echo (SPGR) (TR/TE = 20/1.4 ms; FA: $30^{\circ} ; \mathrm{NEX}=2$; resolution $\left.=500 \times 500 \times 1,000 \mu \mathrm{m}^{3}\right)$. BBB permeabilization was performed using both customized and Definity ${ }^{\circledR}$ microbubbles, and a $500-\mathrm{kHz}$ central frequency focused ultrasound transducer.

In 2019, Aryal et al. [55] successfully delivered liposomes (dually labeled with gadolinium and with fluorescent markers) in rats, then confirming $\mathrm{BBB}$ opening both during MR examination and post-mortem. Sonication was performed with an AP of 0.42 $\mathrm{MPa}$ while gadolinium signal was detected on contrast-enhanced T1-weighted images [rapid acquisition with refocused echoes (RARE); TR/TE = 600/18 ms; echo train length (ETL): 4; matrix size: $128 \times 128$; slice thickness/spacing: $1 \mathrm{~mm} /$ interleaved].

All papers discussed so far have evaluated BBB opening through contrast enhancement achieved by MR-CA extravasation from T1-weighted MRI images. Other papers have employed dynamic contrast-enhanced MRI (DCE$\mathrm{MRI}$ ) to quantitatively evaluate the time evolution of local $\mathrm{BBB}$ permeability induced by FUS application. In this case, T1-weighted baseline images are acquired before and a few minutes after MR-CA administration and used to generate a time-intensity curve (TIC) [56]. A relatively high temporal 
resolution (generally 3.5-6s) is necessary in order to capture the kinetics of CA entry and exit from tissue [57]. Interestingly, a number of pharmacokinetic models have been developed to fit the TIC curve and evaluate all microcirculatory and tissue properties contributing to the MR-signal [58-60]. The general kinetic model (GKM) [58] is most widely employed to describe BBB permeability to MR-CA enhanced by FUS application. In particular, through the GKM, it is possible to obtain quantitative maps of $K_{\text {trans }}$, e.g., the volume transfer constant between blood plasma and within extravascular extra-cellular space (EES), which is enhanced in case of a permeabilized BBB.

In 2011, Vlachos et al. [61] used, for the first time, DCE-MRI to assess focused ultrasound-induced $\mathrm{BBB}$ opening. The authors quantitatively evaluated $\mathrm{BBB}$ permeabilization by generating permeability maps (see Figure 4). To this end, they employed gadodiamide to study changes in contrast-enhanced diffusion within the brain by recording, through a $9.4 \mathrm{~T}$ MRI scanner, DCE-MR images with fast low angle shot magnetic resonance

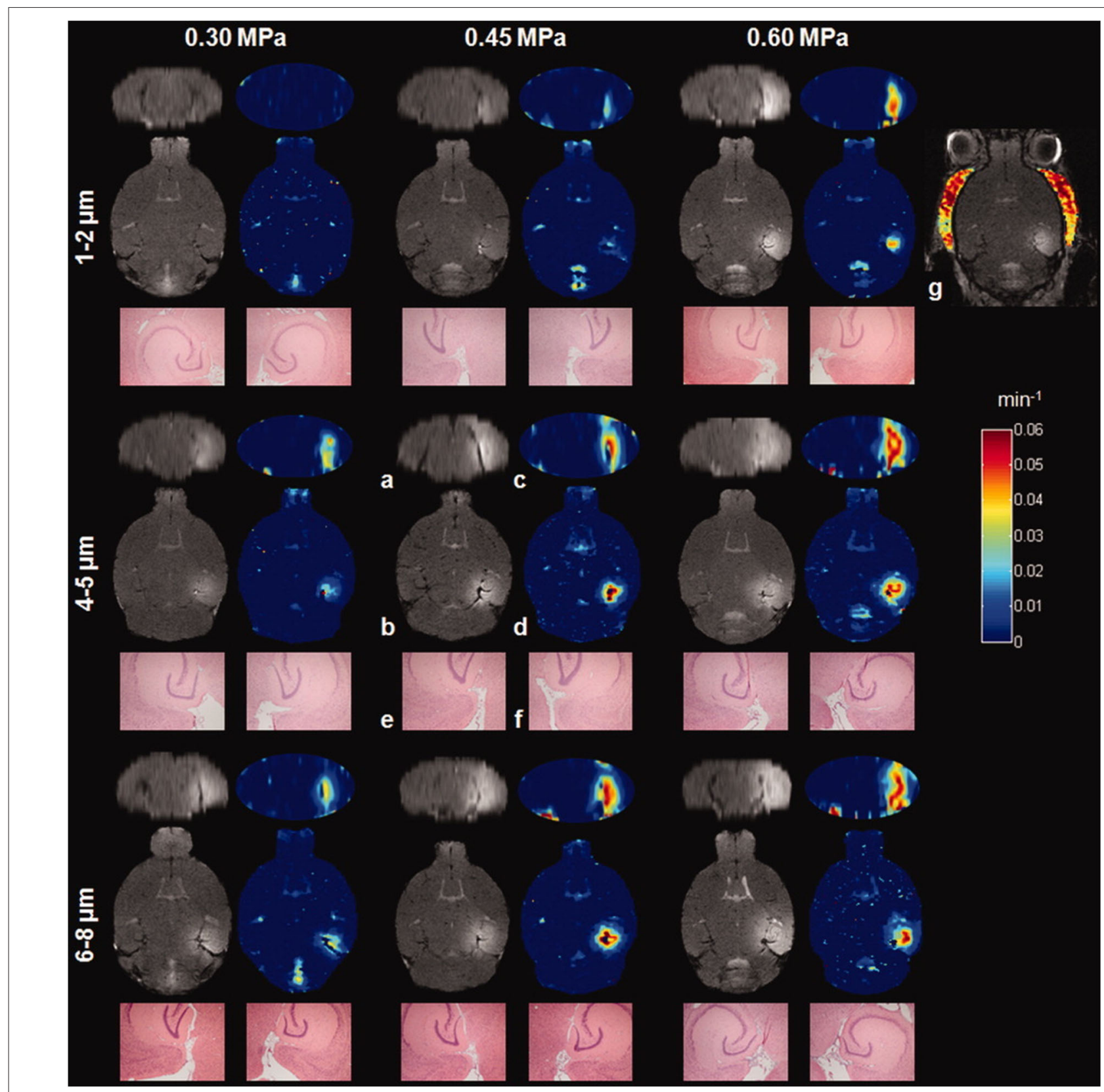

FIGURE 4 | Contrast-enhanced T1-weighed MR images and permeability maps obtained by [61] with different APs (0.30-0.60 MPa) and MBs (sizes ranging between 1 and $8 \mu \mathrm{m})$. As can be noticed from the figure, MR images can reveal a larger disruption of the BBB at the increasing of the APs and the size of MBs used. Reproduced with permission from [61]. 
imaging (FLASH) sequences (acquisition time per volume: $88 \mathrm{~s}$, 40 volumes over $1 \mathrm{~h}$ ). BBB permeabilization was performed at 1.5 $\mathrm{MHz}$, APs of $0.30,0.40,0.60 \mathrm{MPa}$, and by administrating $1 \mu \mathrm{L} / \mathrm{g}$ of microbubbles with a range of hydrodynamic diameters (from 1 to $8 \mu \mathrm{m})$.

Also, the permeability maps described by Chai et al. [62] have been used to demonstrate the existence of imbalanced influx and efflux between the plasma and brain, indicating the existence of directional permeability during FUS-BBB opening. Based on this insight, MRI kinetic monitoring could be useful to monitor pharmacokinetics and pharmacodynamics of drugs delivered to the brain after FUS application. The authors acquired DCEMR images of rat brains after BBB permeabilization and MRCA administration (Magnevist, Gd-DTPA, Berlex Laboratories, Wayne, NJ). They used a 7 T MRI scanner (ClinScan, Bruker, Germany; 7 T) and acquired DCE T1-weighted imaging through a gradient-recall-echo sequence $(\mathrm{TR} / \mathrm{TE}=2.3 / 0.76 \mathrm{~ms}$, slice thickness $=0.8 \mathrm{~mm}$; FAs $=5 / 20^{\circ}$ and matrix size $=192 \times 132$, resolution time: $2.3 \mathrm{~s}$ ).

Wei et al. [63] described the use of contrast enhancement MRI and a transducer working at $400 \mathrm{kHz}$ to evaluate the accuracy of neuronavigation-guided BBB opening with different APs (ranging from 0.26 to $0.56 \mathrm{MPa}$ ) in swine. To this end, the authors acquired T1-weighted MR images (TR/TE 700/11 ms) before and immediately after BBB permeabilization and GdDTPA administration. The longitudinal relaxation rate $\mathrm{R} 1$ was extracted from two T1-weighted gradient recalled-echo images with different flip angles $\left(\mathrm{TR} / \mathrm{TE}=101 / 4.1 \mathrm{~ms}, \mathrm{FA}=20 / 40^{\circ}\right)$ [64] to evaluate $\mathrm{BBB}$ permeability better. All MRI acquisitions were performed on a 3T MR imaging scanner (Trio with Tim; Siemens, Erlangen, Germany).

Fan et al. [65] used DCE-MRI to validate a new technique for monitoring BBB opening based on US imaging. The authors developed a novel, high temporal resolution US-imaging method which was seen to have high concordance with MRI permeability maps collected in rats through a $7 \mathrm{~T}$ scanner (ClinScan 70/30 USR, Bruker, Germany) after US application (2 MHz, 0.5-0.7 $\mathrm{MPa})$ and bolus administration of Gd-DTPA (0.5 ml $/ \mathrm{kg})$. DCEMRI was used MR permeability maps by acquiring a 3-D FLASH T1-weighted sequence $(\mathrm{TE} / \mathrm{TR}=0.76 / 2.31 \mathrm{~ms}$; slice thickness $=$ $0.8 \mathrm{~mm} ; \mathrm{FA}=50 / 200^{\circ}$; matrix size $=192 \times 132$, acquisition time: $20 \mathrm{~s})$.

Sun et al. [66] jointly analyzed permeability maps, calculated from DCE-MR images acquired at $9.4 \mathrm{~T}$ (Bruker, Germany) concomitantly with microbubbles cavitation activity recorded during BBB permeabilization of mice brains. By acquiring DCEMR images through a 2D FLASH T1-weighted sequence (TR/TE $=230 / 2.9 \mathrm{~ms}$, resolution $=130 \times 130 \times 600 \mu \mathrm{m}^{3}$ ), the authors were able to demonstrate a high correlation between $\mathrm{BBB}$ permeability and both stable $\left(r^{2}=0.82\right)$ and inertial cavitation $\left(r^{2}=0.72\right)$ doses. The same association was later verified by Chu et al. [67] using DCE-MRI. In addition, these authors demonstrated that $\mathrm{K}_{\text {trans }}$, and in turn, the permeabilization of the $\mathrm{BBB}$, not only depends on the AP but also on the frequency used during sonication. Indeed, the authors showed that $\mathrm{K}_{\text {trans }}$ values increase with the mechanical index (MI), defined as the peak negative AP over the square root of the frequency (i.e., $\mathrm{MI}=\mathrm{AP} / \sqrt{f}, \mathrm{AP}$ in $\mathrm{MPa}, \mathrm{f}$ in $\mathrm{MHz}$ ). In this study, $\mathrm{BBB}$ permeabilization was performed in rats by using 0.4 or $1 \mathrm{MHz}$ transducers with APs ranging between 0.25 and 0.83 $\mathrm{MPa}$. Animals received a single sonication [10 $\mathrm{ms}$ bursts length, $1 \mathrm{~Hz}$ pulse pulse-repetition frequency, $90 \mathrm{~s}$ exposure duration, 0.2 $\mathrm{mL} / \mathrm{kg}$ SonoVue ${ }^{\circledR}$ (Bracco, Milan, Italy)]. DCE-MR images were acquired with a 7T MR scanner (Bruker Corp., Billerica, MA) by using T1-weighted acquisitions at different flip angles (gradientrecall-echo sequence, $\mathrm{TR} / \mathrm{TE}=2.31 / 0.76 \mathrm{~ms}$, slice thickness $=$ $0.8 \mathrm{~mm}$; slice number $=14 ; \mathrm{FA}=5 / 10 / 15 / 20 / 25 / 30^{\circ}$ ).

A combination of DCE-MRI and susceptibility-weighted (SW) images was employed by Wu et al. [68] to characterize the effect of three different kinds of commonly used microbubbles on $\mathrm{BBB}$ permeabilization. In particular, the authors employed a rat model to test different formulations of UCA: SonoVue, Definity, and USphereTM (Trust Bio Sonic, Taiwan) by using a US transducer working at $0.4 \mathrm{MHz}, 1 \% \mathrm{DC}$, with a $\mathrm{MI}$ of $0.62-1.38$. Their results showed that under identical UCA concentrations and acoustic parameters, these three MBs induced equivalent BBB-opening effects in terms if $\mathrm{BBB}$ permeabilization as well as opening persistence. The authors acquired DCEMRI through a $7 \mathrm{~T}$ magnetic resonance scanner (ClinScan, Bruker, Germany) (gradient-recall-echo sequence, $\mathrm{TR} / \mathrm{TE}=$ $2.31 / 0.76 \mathrm{~ms}$, slice thickness $=0.8 \mathrm{~mm}$, slice number $=14$, flip angle $=5 / 10 / 15 / 20 / 25 / 30^{\circ}$ ) after administrating a T1MRI contrast agent (Gd-DTPA, Magnevist, Berlex Laboratories, Wayne, NJ; $938 \mathrm{Da})$.

In a recent paper published by Yoon et al. [69], DCE-MRI was used to validate $\mathrm{BBB}$ opening in ovine models by detecting MRCA extravasation. Through pharmacokinetic and independent component analysis, the authors showed local disruption of the $\mathrm{BBB}$ without hemorrhage for an $\mathrm{AP}$ of $0.48 \mathrm{MPa}$. DCE-MR images were acquired through a 3 -T MRI scanner (Signa HDxt, GE Medical Systems, Waukesha, WI) by using a fast spin-echo sequence $(\mathrm{TR} / \mathrm{TE}=500 / 13 \mathrm{~ms}$, resolution $=0.7 \times 0.7 \times 3.0$ $\mathrm{mm}^{3}$, echo train length $=4, \mathrm{FA}=90^{\circ}$ ).

As previously mentioned, $\mathrm{BBB}$ permeabilization has been often evaluated through DCE-MRI acquisitions. However, additional studies have employed quantitative MR-CA concentration maps [(CA)-maps] to evaluate the disruption of the BBB. Instead of relying on T1-weighted images (whose contrast may saturate at high concentration of CA sometimes found in the brain after BBB-opening), such methods are based on parametric T1-maps [14, 22, 70, 71].

In this context, Marty et al. [14] used (CA)-maps to evaluate the largest molecular size deliverable across $\mathrm{BBB}$ permeabilized by US application. The authors used a $1.5 \mathrm{MHz}$ transducer $(0.45$ $\mathrm{MPa}, 3 \% \mathrm{DC})$ to sonicate rat brains $5 \mathrm{~s}$ after the administration of SonoVue ${ }^{\complement}$ microbubbles $(1.5 \times 108$ bubbles/mL, $200 \mu \mathrm{L})$. Successively, the authors administered MR-CAs with different hydrodynamic diameters (ranging from 1 to $65 \mathrm{~nm}$ ), finding that the largest size they experimented with $(65 \mathrm{~nm})$ could still be delivered in a regime of APs (below $0.5 \mathrm{MPa}$ ), which can be considered safe (i.e., which do not induce edema or hemorrhage). Here, T1 parametric maps were acquired before and after LIFUS application and MR-CA administration through a $7 \mathrm{~T}$ MRI scanner (Bruker, Germany). In detail, segmented series of FGE 
(fast gradient echo) images were acquired at different time points after magnetization inversion to sample the $\mathrm{T} 1$ recovery curve at multiple times [TR1 $=5 \mathrm{~ms}, \mathrm{TE}=2.5 \mathrm{~ms}$, six segments, 60 inversion times (from 64 to $5,800 \mathrm{~ms}$ ), repetition time between two segments TR2 $=9 \mathrm{~s}, \mathrm{FA}=5^{\circ}$, and Resolution $=0.2 \times 0.2 \times$ $\left.1 \mathrm{~mm}^{3}\right]$.

(CA)-maps have been used by Samiotaki et al. [72] in conjunction with DCE-MR to evaluate BBB opening performed in non-human primates (NHPs). In this study, NHPs were sonicated with APs between 0.20 and $0.60 \mathrm{MPa}$ to open the $\mathrm{BBB}$ both in gray and in white matter. DCE-MR images and (CA)-maps were acquired through 3D Spoiled Gradient Echo (SPGR)/3D T1 Fast field echo (FFE) acquisitions, respectively (acquisition parameters: SPGR: TR/TE: 20/5 ms, FA: 5, 10, 15, 20, $35^{\circ}$, resolution, $0.89 \times 0.89 \times 1 \mathrm{~mm}^{3}$; FFE: TR/TE: $4.2 / 1.7 \mathrm{~ms}$; $\mathrm{FA}=20^{\circ}$, resolution: $\left.1 \times 1 \times 2.5 \mathrm{~mm}^{3}\right)$. At the beginning of the acquisition, an MR-CA (Omniscan ${ }^{\circledR}$, Gd DTPA-BMA, GE Healthcare, Princeton, NJ) was injected intravenously. The authors show in NHP that FUS-induced permeability varied between gray and white matter, likely due to the different vascularization of these regions, and subsequent differences in attainable $\mathrm{MB}$ concentration [73]. In particular, the authors reported that, under sonication, $80 \%$ of the permeabilized regions belong to white matter. In addition, the authors observed an increase of permeabilization as AP increased. This result suggests that FUS impact $\mathrm{BBB}$ in gray and white matter in a differential manner, likely due to their different vascularization and subsequent differences in attainable MB concentration.

All the articles presented in this section were found on PubMed using the keywords MRI and FUS and BBB-opening. The search was executed on 20/12/2019. Table 1 details the MR-CAs as well as the details of MRI acquisitions used in the $\mathrm{BBB}$-opening studies referenced.

\section{MR IMAGING TO EVALUATE BBB CLOSURE}

FUS application allows obtaining a reversible disruption of the BBB by creating gaps between endothelial cells. These gaps begin closing right after US application, progressively reversing, over time, the enhancement in the ability of small molecules to cross the blood to the brain. Using MRI, it is possible to study the dynamics of particle uptakes during $\mathrm{BBB}$ closure. This can be achieved by injecting MR-CAs smaller than $65 \mathrm{~nm}$ [14] and acquiring T1-w images at different time points after FUS application. In turn, this has allowed extensive use of MR acquisitions to optimize the ultrasound protocol in preclinical studies.

In 2009, Yang et al. [76] evaluated, through MRI acquisitions using a 3 T MRI system (TRIO 3-T MRI, Siemens MAGNETOM, Germany), the effect of microbubble dose on the duration of FUS-induced BBB disruption at an acoustic power of $1.43 \mathrm{~W}$. Sonications were performed at a frequency of $1 \mathrm{MHz}$ with a $5 \%$ DC, $15 \mathrm{~s}$ after the injection of SonoVue ${ }^{(}$. T1- and T2- weighted images were acquired after MR-CA administration (Omniscan, Gd DTPA-BMA, GE Healthcare, Cork, Ireland). The authors demonstrated that the BBB-closure time exceeds $4 \mathrm{~h}$ for high doses $(450 \mu \mathrm{L} / \mathrm{kg})$ of MBs.

The association between the contrast-enhanced (CE) MRI signal and the duration of FUS-BBB disruption was investigated in 2010 by Yang et al. [77]. The authors imaged 48 rats through a $3 \mathrm{~T}$ MRI scanner (TRIO, Siemens Magnetom, Erlangen, Germany) for up to $1 \mathrm{~h}$ after FUS application (burst length of $50 \mathrm{~ms}$, DC of 5\%, AP between 1.43 and $4.29 \mathrm{~W}$, SonoVue ${ }^{()}$at 150 $\mu \mathrm{L} / \mathrm{kg})$. They demonstrated the existence of a strong correlation between CE MRI signal and CA extravasation, which persisted until $1 \mathrm{~h}$ after sonication. Successively, other authors employed DCE to study how different acoustic parameters can affect BBB closure dynamics, examining periods of up to several days after FUS application.

In 2012, Samiotaki et al. [78] used DCE-MRI to show how BBB closure dynamics depends on APs and microbubble size employed for vascular permeabilization. MRI data were acquired from the day of the experiments until 7 days later. Each MRI session a 9.4 T MRI scanner (performed on a scanner by Bruker Medical; Boston, MA) included a pre- and a post-MRCA injection (Omniscan ${ }^{\text {TM }}$ (Gd-DTPA-BMA) T1-weighted 2D FLASH acquisitions (TR/TE: $230 / 3.3 \mathrm{~ms}, \mathrm{FA}: 70^{\circ}$, resolution $=$ $86 \times 86 \times 500 \mu \mathrm{m})$. The authors found that the duration of the $\mathrm{BBB}$ opening in mice was extended from 1 to 5 days as the UCA size increased from 1 to $8 \mu \mathrm{m}$. BBB closure dynamic was also seen to depend on APs, with variations between 1 and 3 days for an AP of 0.3 and $0.6 \mathrm{MPa}$, respectively.

In 2013, the same group used DCE and T1-weighted MRI to study changes in the reversibility timeline of FUS-induced BBB opening for different pulse lengths (PLs). Sonications with APs ranging between 0.30 and $0.60 \mathrm{MPa}$ [79] and pulse lengths (PL) of $0.067,0.67$, and $6.7 \mathrm{~ms}$ and MRI acquisitions similar to what employed in [78] demonstrated that BBB closure rate decreases with the increase of both of PL and AP. However, their results suggested that in the investigated range of PLs and APs, the BBB consistently closes within 3 days after its disruption. In this study, all experiments were performed in mice with post-contrast DCE MR images acquired in a 9.4 T MRI scanner (Bruker Medical; Boston, MA) using 2D FLASH T1-weighted sequences (TR/TE: 230/3.3 ms, resolution $100 \times 100 \mu \mathrm{m}$, slice thickness: $400 \mu \mathrm{m}$ ).

In 2015, Sun et al. [66] used DCE-MRI, acquired at 9.4 $\mathrm{T}$ (Bruker, Germany) in a mouse model, to quantitatively evaluate the duration of $\mathrm{BBB}$ permeability and correlate it with microbubbles cavitation doses acquired during permeabilization. The authors found that stable cavitation was associated with the duration of BBB opening $\left(r^{2}=0.77\right)$ in a safe regime of APs below $0.60 \mathrm{MPa}$ for up until 6 days after the experiments. Here, DCEMRI was performed using a 2D FLASH T1-weighted sequence $\left(\mathrm{TR} / \mathrm{TE}=230 / 2.9 \mathrm{~ms}\right.$, resolution $\left.=130 \times 130 \times 600 \mu \mathrm{m}^{3}\right)$.

In 2012, Marty et al. [14] presented a comprehensive study of $\mathrm{BBB}$ closure dynamics after FUS-induced disruption as a function of the size of delivered molecules. The authors permeabilized $\mathrm{BBB}$ in rat brains by using a $1.5 \mathrm{MHz}$ transducer at fixed acoustic parameters (0.45 MPa, 3\% DC, SonoVue microbubbles $(1.5 \times 108$ bubbles/mL, $200 \mu \mathrm{L})$. They focused on the study of concentration uptake within $24 \mathrm{~h}$ after BBB permeabilization, employing a range of different hydrodynamic 
TABLE 1 | Specifications of studies, included in this narrative review, using MR-CA administration to evaluate the opening of the BBB induced by FUS application.

\begin{tabular}{|c|c|c|c|c|c|}
\hline References & Main findings of the study & $\begin{array}{l}\text { Clinical (C)/ } \\
\text { Pre-clinical (P) }\end{array}$ & MRI scanner & MRI sequence & MR-CA \\
\hline $\begin{array}{l}\text { Hynynen et al. } \\
\text { [21] }\end{array}$ & $\begin{array}{l}\text { Feasibility of BBB opening through } \\
\text { FUS application }\end{array}$ & P (Rabbit) & $\begin{array}{l}1.5 \mathrm{~T} \text { (GE Medical } \\
\text { Systems) }\end{array}$ & $\begin{array}{l}\text { T1-w fast SE }(T R / T E=500 / 17 \mathrm{~ms} ; \text { spatial resolution } \\
\left.(x, y, z)=400 \times 400 \mu \mathrm{m}^{2} \times 1.5 \mathrm{~mm}\right)\end{array}$ & Gd-DTPA \\
\hline Choi et al. [46] & BBB opening through intact skulls & P (Mice) & $\begin{array}{l}9.4 \mathrm{~T} \text { (Bruker } \\
\text { medical) }\end{array}$ & $\begin{array}{l}\text { T1-w (FOV: } 1.92 \times 1.92 \mathrm{~cm} \text {; matrix size: } 256 \times 256 \text {; } \\
\text { slice thickness: } 0.6 \mathrm{~mm} \text {; interslice thickness: } 0.70 \mathrm{~mm}\end{array}$ & Gd DTPA-BMA \\
\hline Choi et al. [47] & $\begin{array}{l}\text { BBB opening through intact skulls with } \\
\text { lower acoustic pressures ( } 0.8 \mathrm{MPa})\end{array}$ & P (Mice) & $\begin{array}{l}9.4 \mathrm{~T} \text { (Bruker } \\
\text { Medical) }\end{array}$ & $\begin{array}{l}\text { T1-w SE }(T R / T E=246.1 / 10 \mathrm{~ms} \text {; matrix size: } 256 \times \\
\left.\text { 256; FOV: } 1.92 \times 1.92 \mathrm{~cm}^{2} \text {; slice thickness: } 0.6 \mathrm{~mm}\right)\end{array}$ & Gd DTPA-BMA \\
\hline $\begin{array}{l}\text { McDannold } \\
\text { et al. [48] }\end{array}$ & $\begin{array}{l}\text { Differential effects of acoustic } \\
\text { parameters and UCA dose on } \\
\text { FUS-induced BBB opening }\end{array}$ & P (Rabbit) & $\begin{array}{l}1.5 \mathrm{~T} \text { (GE Medical } \\
\text { systems) }\end{array}$ & $\begin{array}{l}\text { T1-w fast SE (TR/TE: } 500 / 15 \text { to } 23 \text { ms; matrix size: } \\
256 \times 256 \text {; FOV: } 10 \mathrm{~cm} \text {; slice thickness: } 1.5 \mathrm{~mm} \text {; } \\
\text { interslice spacing: } 1.5 \mathrm{~mm} \text { ) }\end{array}$ & Gd-DTPA \\
\hline Tung et al. [52] & $\begin{array}{l}\text { BBB opening induced without cellular } \\
\text { damage and } \mathrm{AP} \text { below } 0.5 \mathrm{MPa}\end{array}$ & P (Mice) & $\begin{array}{l}9.4 \mathrm{~T} \text { (Bruker } \\
\text { medical) }\end{array}$ & $\begin{array}{l}\text { T1-w SNAP GE }\left(T R / T E=20 / 4 \mathrm{~ms}, \mathrm{FA}=25^{\circ}\right. \\
\left.\text { resolution }(x, y, z)=75 \times 75 \times 312.5 \mu \mathrm{m}^{3}\right)\end{array}$ & Gd DTPA-BMA \\
\hline $\begin{array}{l}\text { Marquet et al. } \\
{[54]}\end{array}$ & $\begin{array}{l}\text { AP below } 0.6 \mathrm{MPa} \text { to permeabilize } \\
\text { BBB in NHP }\end{array}$ & $\mathrm{P}(\mathrm{NHP})$ & $3 \mathrm{~T}$ & $\begin{array}{l}\text { T1-w 3D Spoiled GE }\left(T R / T E=20 / 1.4 \mathrm{~ms} ; \mathrm{FA}: 30^{\circ} ;\right. \\
\left.\mathrm{NEX}=2 ; \text { resolution }=500 \times 500 \times 1,000 \mu \mathrm{m}^{3}\right)\end{array}$ & Gd-DTPA \\
\hline Aryal et al. [55] & $\begin{array}{l}\text { BBB opening to deliver liposomes to } \\
\text { the brain }\end{array}$ & P (Mice) & $\begin{array}{l}\text { 7-T MRI (Biospec, } \\
\text { bruker) }\end{array}$ & $\begin{array}{l}\text { T1-w RARE }[T R / T E=600 / 18 \mathrm{~ms} \text {; echo train length } \\
(E T L): 4 \text {; matrix size: } 128 \times 128 \text {; slice } \\
\text { thickness/spacing: } 1 \mathrm{~mm} / \text { interleaved] }\end{array}$ & $\begin{array}{l}\text { Liposomes labeled } \\
\text { with gadolinium } \\
\text { and fluorescent } \\
\text { markers }\end{array}$ \\
\hline $\begin{array}{l}\text { Vlachos et al. } \\
{[61]}\end{array}$ & $\begin{array}{l}\text { First evaluation of BBB opening } \\
\text { through DCE-MRI acquisitions }\end{array}$ & P (Mice) & $\begin{array}{l}9.4 \mathrm{~T} \text { (Bruker } \\
\text { medical) }\end{array}$ & $\begin{array}{l}\text { DCE-MRI, 2D FLASH T1-w (spatial resolution: } 130 \times \\
130 \mu \mathrm{m} 2 ; \text { slice thickness } 600 \mu \mathrm{m} \text { no interslice gap; } \\
\text { FA: } 70^{\circ}, \mathrm{TR} / \mathrm{TE}=230 / 2.9 \mathrm{~ms} \text {, Number of } \\
\text { Excitations }=4 \text {, scan time: } 88 \mathrm{~s} \text {. Forty dynamic } \\
\text { acquisitions over a total period of } 60 \mathrm{~min} \text { ) }\end{array}$ & Gd-DTPA \\
\hline Chai et al. [62] & $\begin{array}{l}\text { Existence of directional permeability } \\
\text { during FUS-BBB opening }\end{array}$ & P (Mice) & $7 \mathrm{~T}$ (Bruker) & $\begin{array}{l}\text { DCE- T1-w gradient-recall-echo } \\
(T R / T E=2.3 / 0.76 \mathrm{~ms} \text {, slice thickness }=0.8 \mathrm{~mm} \text {; } \\
\text { FAs }=5 / 20^{\circ} \text { and matrix size }=192 \times 132 \text {, resolution } \\
\text { time: } 2.3 \mathrm{~s})\end{array}$ & Gd-DTPA \\
\hline Wei et al. [63] & $\begin{array}{l}\text { Evaluation of the accuracy of } \\
\text { neuronavigation-guided BBB opening }\end{array}$ & $\mathrm{P}$ (Swine) & 3T (Trio, Siemens) & $\begin{array}{l}\text { R1-maps, gradient-recalled-echo }(T R / T E=101 \\
\left./ 4.1 \mathrm{~ms}, \mathrm{FA}=20 / 40^{\circ}\right)\end{array}$ & Gd-DTPA \\
\hline Fan et al. [65] & $\begin{array}{l}\text { Validation of a new US-based } \\
\text { technique for monitoring BBB opening } \\
\text { correlating with DCE-MRI findings }\end{array}$ & P (Rats) & $\begin{array}{l}7 \mathrm{~T}(\mathrm{ClinScan}, \\
\text { bruker) }\end{array}$ & $\begin{array}{l}\text { DCE 3D FLASH T1-w }(T E / T R=0.76 / 2.31 \mathrm{~ms} \text {; slice } \\
\text { thickness }=0.8 \mathrm{~mm} ; \mathrm{FA}=50 / 200^{\circ} ; \text { matrix } \\
\text { size }=192 \times 132, \text { acquisition time: } 20 \mathrm{~s}) .\end{array}$ & Gd-DTPA \\
\hline Sun et al. [66] & $\begin{array}{l}\text { Correlation between BBB permeability } \\
\text { and cavitation doses }\end{array}$ & P (Mice) & 9.4 T (Bruker) & $\begin{array}{l}\text { DCE 2D FLASH T1-weighted sequence } \\
(T R / T E=230 / 2.9 \text { ms, resolution }=130 \times 130 \times 600 \\
\left.\mu \mathrm{m}^{3}\right)\end{array}$ & Gd-DTPA \\
\hline Chu et al. [67] & $\begin{array}{l}\text { BBB opening depends on the } \\
\text { frequency used during sonication }\end{array}$ & P (Mice) & $7 \mathrm{~T}$ (Bruker) & $\begin{array}{l}\text { DCE T1-w gradient-recall-echo sequence } \\
(\mathrm{TR} / \mathrm{TE}=2.31 / 0.76 \mathrm{~ms} \text {, slice thickness }=0.8 \mathrm{~mm} \text {; } \\
\left.\text { slice number }=14 ; \mathrm{FA}=5 / 10 / 15 / 20 / 25 / 30^{\circ}\right)\end{array}$ & Gd-DTPA \\
\hline Wu et al. [68] & $\begin{array}{l}\text { Characterization of the effect of three } \\
\text { different kinds of commonly used } \\
\text { microbubbles on BBB } \\
\text { permeabilization. }\end{array}$ & P (Rat) & $\begin{array}{l}7 \mathrm{~T} \text { (ClinScan, } \\
\text { Bruker) }\end{array}$ & $\begin{array}{l}\text { DCE-MRI gradient- recall-echo sequence, } \\
(\mathrm{TR} / \mathrm{TE}=2.31 / 0.76 \mathrm{~ms}, \text { slice thickness }=0.8 \mathrm{~mm} \text {, } \\
\text { slice number }=14, \text { flip angle }=5 / 10 / 15 / 20 / 25 / 30^{\circ} \text { ) }\end{array}$ & Gd-DTPA \\
\hline $\begin{array}{l}\text { Yoon et al. } \\
\text { [69] }\end{array}$ & $\begin{array}{l}\text { BBB opening without hemorrhages in } \\
\text { large animal (ovine) models }\end{array}$ & P (Sheep) & $\begin{array}{l}\text { 3T (Signa HDxt, } \\
\text { GE medical } \\
\text { systems) }\end{array}$ & $\begin{array}{l}\text { DCE T1-w fast SE }(T R / T E=500 / 13 \mathrm{~ms} \text {, } \\
\text { resolution }=0.7 \times 0.7 \times 3.0 \mathrm{~mm}^{3} \text {, echo train } \\
\left.\text { length }=4, F A=90^{\circ}\right)\end{array}$ & Gd-DTPA \\
\hline $\begin{array}{l}\text { Marty et al. } \\
{[14]}\end{array}$ & $\begin{array}{l}\text { Evaluation of the molecular size } \\
\text { deliverable across permeabilized BBB }\end{array}$ & P (Rats) & $7 \mathrm{~T}$ (Bruker) & $\begin{array}{l}(\mathrm{CA}) \text {-maps FGE }(\mathrm{TR} 1=5 \mathrm{~ms}, \mathrm{TR} 2=9 \mathrm{~s} \\
\mathrm{TE}=2.5 \mathrm{~ms} \text {, six segments, } 60 \text { inversion times (from } \\
64 \text { to } 5,800 \mathrm{~ms}), \mathrm{FA}=5^{\circ}, \text { and resolution }=0.2 \times 0.2 \\
\times 1 \mathrm{~mm}^{3} \text { ) }\end{array}$ & $\begin{array}{l}\text { Gd-DOTA, P846, } \\
\text { P792 }\end{array}$ \\
\hline $\begin{array}{l}\text { Samiotaki } \\
\text { et al. [72] }\end{array}$ & $\begin{array}{l}\text { BBB opening varies among white and } \\
\text { gray matter regions }\end{array}$ & $\mathrm{P}(\mathrm{NHP})$ & 3T (Philips) & $\begin{array}{l}\text { DCE-T1w (SPGR: TR/TE: } 20 / 5 \mathrm{~ms} \text {, FA: } 5,10,15,20 \text {, } \\
35^{\circ} \text {, resolution, } 0.89 \times 0.89 \times 1 \mathrm{~mm}^{3} \text {; FFE: TR/TE: } \\
\left.4.2 / 1.7 \mathrm{~ms} \text {; FA }=20^{\circ} \text {, resolution: } 1 \times 1 \times 2.5 \mathrm{~mm}^{3}\right) \\
(\mathrm{CA}) \text {-maps }\left(\mathrm{FFE}: \text { TR/TE: } 4.2 / 1.7 \mathrm{~ms} ; \mathrm{FA}=20^{\circ}\right. \\
\text { resolution: } 1 \times 1 \times 2.5 \mathrm{~mm}^{3} \text { ) }\end{array}$ & Gd-DTPA-BMA \\
\hline $\begin{array}{l}\text { Lipsman et al. } \\
\text { [32] }\end{array}$ & BBB opening evaluation & $\begin{array}{l}\mathrm{C} \text { (Alzheimer } \\
\text { patients) }\end{array}$ & $\begin{array}{l}\text { 3T MRI scanner } \\
\text { (Signa MR750; GE } \\
\text { Healthcare }\end{array}$ & T1-w (other info: not provided) & $\begin{array}{l}\text { Gd-based MR (CA) } \\
\text { (other info: not } \\
\text { provided) }\end{array}$ \\
\hline $\begin{array}{l}\text { Meng et al. } \\
{[74]}\end{array}$ & BBB opening evaluation & $\begin{array}{l}\text { C (Alzheimer } \\
\text { patients) }\end{array}$ & $\begin{array}{l}3 \mathrm{~T} \text { (Signa MR750; } \\
\text { GE Healthcare) }\end{array}$ & $\begin{array}{l}\text { T1-w 3D fast spoiled gradient echo (176 slices of } \\
1 \mathrm{~mm} \text { thickness, TR/TE }=7.65 / 2.94 \mathrm{~ms} \text {, matrix } \\
\text { size }=265 \times 265)\end{array}$ & $\begin{array}{l}\text { Gd-based MR (CA) } \\
\text { (other info: not } \\
\text { provided) }\end{array}$ \\
\hline $\begin{array}{l}\text { Abraho et al. } \\
{[75]}\end{array}$ & BBB opening evaluation & $\begin{array}{l}\mathrm{C} \text { (Amyotrophic } \\
\text { lateral sclerosis } \\
\text { patients) }\end{array}$ & $\begin{array}{l}3 \mathrm{~T} \text { (Signa MR750; } \\
\text { GE Healthcare) }\end{array}$ & $\begin{array}{l}\text { T1-w 3D fast spoiled gradient echo (slices of } 1 \mathrm{~mm} \\
\text { thickness, TR/TE }=7.65 / 2.94 \mathrm{~ms} \text {, matrix size }=265 \\
\times 265 \text { ) }\end{array}$ & $\begin{array}{l}\text { Gd-based MR (CA) } \\
\text { (other info: not } \\
\text { provided) }\end{array}$ \\
\hline
\end{tabular}


diameters (between 1 and $65 \mathrm{~nm}$ ) administered seven times per day. After each administration, quantitative (CA)-maps were recorded through a $7 \mathrm{~T}$ MRI scanner (Bruker, Germany) by using a segmented series of FGE sequences (TR1 $=5 \mathrm{~ms}, \mathrm{TE}=$ $2.5 \mathrm{~ms}$, six segments, 60 inversion times (from 64 to $5,800 \mathrm{~ms}$ ), $\mathrm{FA}=5^{\circ}$, and Resolution $\left.=0.2 \times 0.2 \times 1 \mathrm{~mm}^{3}\right)$. These maps allowed the time-dependent quantification particles delivered and demonstrated that the BBB remains permeable to small MRCA ( $~ 1 \mathrm{~nm}$ diameter) up to $24 \mathrm{~h}$ after US application. Instead, for molecules of $65 \mathrm{~nm}$, the BBB remains open for $<15$ min after sonication. Also, the authors proposed a model able to relate the half closure time $\left(\mathrm{t} \frac{1}{2}\right)$ to the molecular hydrodynamic diameter. The same group also related the expression of $t \frac{1}{2}$ as a function of the size of delivered agents to BBB closure rate and FUS-induced BBB gap sizes [80].

All the articles presented in this section were found on PubMed using the keywords MRI AND FUS AND BBB-opening OR MRI AND FUS and BBB-closure. Both searches were executed on $10 / 1 / 2020$.

\section{MRI TO INVESTIGATE THE EFFECTS OF FUS ON THE BRAIN}

In this section, we introduce MRI techniques used in literature to evaluate the effects of FUS application on brain structure and function. Papers described in this section were the result of a PubMed search using the keywords MRI AND FUS AND BBB-opening, MRI AND FUS AND SAFE AND BBB-opening, MRI AND FUS AND safety AND BBB-opening, functional MRI AND FUS AND BBB-opening, fMRI AND FUS AND BBBopening. Searches were executed on 15/01/2019. Papers focusing on the topics discussed in this paragraph have then been selected. In Table 2 specifications of all cited studies investigating BBB closure dynamics are reported.

\section{MRI Methods to Ensure Safe BBB Opening}

In this section, we introduce MR methods suitable to investigate the safety of LIFUS application to the brain. One of the main safety concerns when applying US through the intact skull is the possibility of damaging the surface of the brain thought he mechanism of bone heating [81, 82]. To avoid this issue, most of the work initially performed in this field was conducted by sonicating the brain after craniotomy and by running concomitant MRI thermometry [21,83]. The latter technique is capable of recording changes in temperature-dependent proton resonant frequency [84].

In 2001, Hynynen et al. [21] adopted MRI thermometry to monitor temperature rise in the brain during sonication after craniotomy. This method was based on repeated spoiled gradient-echo MRI acquisitions (TR/TE $=40.9 / 19.9 \mathrm{~ms} ; \mathrm{FA}=$ $30^{\circ}$; resolution $=0.5 \times 0.7 \times 1 \mathrm{~mm}^{3}$ ). MR images were obtained during rabbit brain sonication using APs ranging from 0.2 to $11 \mathrm{~W}$ and were used to keep the accumulated dose below a safety threshold by keeping brain temperature below $43^{\circ} \mathrm{C}$ within $1 \mathrm{~min}$. In 2004, McDannold et al. [23] published the first MRI method able to monitor heating produced by ultrasound absorption in the skull. In this study, fast spoiled gradient-echo MRI acquisitions generated temperature images $\left(\mathrm{TR} / \mathrm{TE} 39.5 / 19.3 \mathrm{~ms}, \mathrm{FA}=30^{\circ}, \mathrm{FOV}=20 \times 15 \mathrm{~cm}\right.$, slice thickness $=5 \mathrm{~mm}$, matrix $=256 \times 96$ ), while sonicating pigs in different brain locations (frequency $=690 \mathrm{kHz}$; acoustic power $=8.2-16.5 \mathrm{~W}$ ). Phase-difference images were generated to obtain local estimates of temperature changes [84]. Safe openings were obtained in humans by applying acoustic parameters tested on porcine models [85] while monitoring local temperature through MR-thermometry techniques [32].

Another safety issue that may be occurring when $\mathrm{BBB}$ is disrupted through sonication is local edema or hemorrhage [86]. These events can be detected through T2-weighted MR imaging, where they produce hyper- and hypointense signals, respectively $[87,88]$. In particular, cerebral microbleeds are

TABLE 2 | Specifications of studies, included in this narrative review, using MR-CA administration to investigate BBB closure dynamic after US application.

\begin{tabular}{|c|c|c|c|c|c|}
\hline References & Main findings of the study & $\begin{array}{l}\text { Animal } \\
\text { species }\end{array}$ & MRI scanner & MRI sequence & MR-CA \\
\hline Yang et al. [76] & $\begin{array}{l}\text { Differential effect of microbubble dose } \\
\text { on the duration of FUS-induced BBB } \\
\text { disruption }\end{array}$ & Rat & 3T (TRIO Siemens) & $\begin{array}{l}\text { T1-w multi-slice SE }(20 \text { slices, TR/TE }=435 / 12 \mathrm{~ms} \text {; } \\
\text { in-plane resolution }=195 \times 390 \mu \mathrm{m}^{2} ; \text { slice } \\
\text { thickness }=1.5 \mathrm{~mm})\end{array}$ & Gd DTPA-BMA \\
\hline Yang et al. [77] & $\begin{array}{l}\text { BBB-opening last for at least } 1 \mathrm{~h} \text { after } \\
\text { sonication }\end{array}$ & Rat & 3T (TRIO Siemens) & $\begin{array}{l}\text { T1-w SE }(T R / T E=435 / 12 \text { ms; matrix }=154 \times 256 \\
\text { slice thickness }=1.5 \mathrm{~mm} ; 20 \text { slices })\end{array}$ & Gd-DTPA \\
\hline $\begin{array}{l}\text { Samiotaki et al. } \\
\text { [78] }\end{array}$ & $\begin{array}{l}\text { BBB closure dynamics depends on } \\
\text { APs and microbubble size }\end{array}$ & Mice & 9.4 T (Bruker) & $\begin{array}{l}\text { T1-w 2D FLASH acquisitions (TR/TE: } 230 / 3.3 \mathrm{~ms} \text {, } \\
\left.\text { FA: } 70^{\circ} \text {, resolution }=86 \times 86 \times 500 \mu \mathrm{m}^{3}\right)\end{array}$ & Gd-DTPA-BMA \\
\hline $\begin{array}{l}\text { Samiotaki et al. } \\
\text { [79] }\end{array}$ & $\begin{array}{l}\text { BBB closure rate decreases with the } \\
\text { increase of both of Pulse lengths and } \\
\text { AP }\end{array}$ & Mice & 9.4 T (Bruker) & $\begin{array}{l}\text { DCE T1-w (TR/TE: } 230 / 3.3 \mathrm{~ms} \text {, resolution } 100 \times \\
\left.100 \mu \mathrm{m}^{2}, \text { slice thickness: } 400 \mu \mathrm{m}\right)\end{array}$ & Gd-DTPA-BMA \\
\hline Sun et al. [66] & $\begin{array}{l}\text { Duration of BBB permeability } \\
\text { correlates with microbubbles } \\
\text { cavitation }\end{array}$ & Mice & 9.4 T (Bruker) & $\begin{array}{l}\text { DCE T1-w }(2 \mathrm{D} \text { FLASH, TR/TE }=230 / 2.9 \mathrm{~ms} \text {, spatial } \\
\text { resolution: } 130 \times 130 \mu \mathrm{m}^{2} \text {, slice thickness: } \\
600 \mu \mathrm{m}) .\end{array}$ & Gd-DTPA-BMA \\
\hline Mary et al. [14] & $\begin{array}{l}\text { BBB closure dynamics as a function } \\
\text { of the size of delivered molecules. }\end{array}$ & Rats & $7 \mathrm{~T}$ (Bruker) & $\begin{array}{l}(\mathrm{CA}) \text { - maps FGE }(\mathrm{TR} 1=5 \mathrm{~ms}, \mathrm{TR} 2=9 \mathrm{~s}, \\
\mathrm{TE}=2.5 \mathrm{~ms} \text {, six segments, } 60 \text { inversion times (from } \\
64 \text { to } 5,800 \mathrm{~ms}), \mathrm{FA}=5^{\circ}, \text { and Resolution }=0.2 \times \\
0.2 \times 1 \mathrm{~mm}^{3} \text { ) }\end{array}$ & $\begin{array}{l}\text { Gd-DOTA P846, } \\
\text { P792 }\end{array}$ \\
\hline
\end{tabular}


easily detectable through MRI since they generate local magnetic field inhomogeneities, which results in faster signal decay [89]. Among available MRI pulse sequences, T2*-weighted MRI, and SWI, have proved to be the most useful in detecting hemorrhage.

For this reason, in 2008, Liu et al. [24] investigated the feasibility of SWI for identifying tissue hemorrhage associated with BBB disruption induced by FUS in a rat model. The authors demonstrated that SWI was more sensitive than T2-weighed MRI in detecting hemorrhages and recovery processes of damaged tissues after sonication.

In 2013, Wei et al. [63] modified a heavy $\mathrm{T} 2{ }^{*}$-weighted fast low-angle shot sequence $\left(\mathrm{TR} / \mathrm{TE}=28 / 20 \mathrm{~ms} ; \mathrm{FA}=15^{\circ}\right)$ implemented on a $3 \mathrm{~T}$ MRI scanner (Trio with Tim; Siemens, Erlangen, Germany) to perform SWI. They were able to identify intracerebral hemorrhaging caused by excessive FUS exposure in large-animal (swine) experiments.

A year later, Fan et al. [90] used SWI to demonstrate that when submicron bubbles are exposed to resonant-frequency matched FUS inertial cavitation phenomena, the risks of erythrocyte extravasations are significantly reduced. The authors delivered FUS with APs of 0.1-4.5 MPa to rat brains using either in-house manufactured submicron bubbles or SonoVue ${ }^{(C)}$ microbubbles, and two different US transducer operating at 1 and $10 \mathrm{MHz}$ (where the latter is resonant with the stable cavitation frequency of submicron bubbles). SWI was performed on a 3-T MRI system (Trio with Tim, Siemens, Erlangen, Germany) with the following parameters: $\mathrm{TR} / \mathrm{TE}=28 / 20 \mathrm{~ms} ; \mathrm{FA}=15^{\circ}, 16$ slices, resolution of $0.3 \times 0.3 \times 0.7 \mathrm{~mm}^{3}$. The same MRI technique has been later employed by $\mathrm{Wu}$ et al. [91] to demonstrate that stable microbubble cavitation does not cause edema or hemorrhage in $\mathrm{BBB}$ opening experiments performed in large animals (NHPs).

Liu et al. [92] investigated a fully flow-compensated T2*weighted imaging method enhanced by superparamagnetic iron oxide (SPIO) particles to distinguish FUS-induced BBB opening from brain hemorrhages. The $\mathrm{T}^{*}$-weighted signal is dependent both on spin-spin interaction and on spin coherence loss resulting from the susceptibility-induced field variations surrounding SPIO particles. Rat brains were sonicated at 1.5 $\mathrm{MHz}$, pulse repetition frequency (PRF) of $1 \mathrm{~Hz}$, and APs of 1.1, 1.9, 2.45, and 3.5 $\mathrm{MPa}$. Follow-up $\mathrm{T} 2{ }^{*}$-weighted imaging was performed every 7 days for up to 35 days by using a $3 \mathrm{~T}$ scanner (Trio with Tim, Magnetom, Siemens, Erlangen, Germany) through a $\mathrm{T}^{*}$-weighted $3 \mathrm{D}$ FLASH sequence acquired before and after SPIO administration $\left(\mathrm{TR} / \mathrm{TE}=28 / 20 \mathrm{~ms}\right.$; FA $=15^{\circ}$, resolution $=0.3 \times 0.3 \times 0.7 \mathrm{~mm}^{3}$ ). This study showed that $\mathrm{T}^{*}$ weighted MR images with and without SPIO particles could be of aid in differentiating between sonicated areas and hemorrhages.

In 2018, Jones et al. [93] published a new method to perform transcranial microbubble imaging suitable to calibrate exposure levels when performing BBB disruption. In this work, performed on rabbits, the authors used an MRI-compatible ultrasound phased array system installed within a 3T scanner (Magnetom Prisma; Siemens Healthcare, Erlangen, Germany). After the administration of a gadolinium-based MR-CA (GadovistTM; Bayer Inc., Toronto, ON, Canada), the authors acquired CET1-weighted images to evaluate $\mathrm{BBB}$ permeability, as well as
T2- and $\mathrm{T} 2 *$-weighted images for evaluating the presence of edemas of hemorrhages, respectively. The MRI findings reported by the authors suggested that $3 \mathrm{D}$ subharmonic imaging can be used to calibrate exposure levels for safe FUS-induced volumetric BBB opening.

\section{MRI Methods to Investigate Brain Functionality After BBB Opening}

Since the first use of FUS for BBB permeabilization, conjectures about potential changes in brain function induced by FUS have emerged. Among non-invasive tools for functional brain imaging, functional Magnetic Resonance Imaging (fMRI) is the most popular. fMRI offers a much higher spatial resolution than other brain functional imaging techniques such as EEG, at the expense of a lower time resolution. fMRI techniques are based on blood oxygenation level-dependent (BOLD) imaging, a technique designed to detect signal changes originated by the variation of oxy- and deoxyhemoglobin ratio [94]. This ratio changes when the neuron firing rate increases above basal levels and local energy demand increases rapidly, requiring more oxygen in the surrounding tissue and, in turn, affecting variations in the BOLD signal [95]. This regional BOLD response is often modeled as a so-called Hemodynamic Response Function (HRF) [96]. Despite the well-characterized physiological functioning of the hemodynamic response, the neurobiological details of this neurovascular coupling are largely unknown. Neurovascular coupling not only controls blood flow-hence modulating oxygen levels-but it also has some direct neurometabolic effects; for instance, following the neuronal glucose depletion, the permeability of the BBB for glucose is enhanced by the stimulation of the glucose transporter 1 (GLUT 1) [97]. The $\mathrm{BBB}$ is also responsible for controlling the transport of other substances necessary for neuronal physiology, including other energy substrates (such as lactate, acetate, ketone bodies), neurotransmitter pre-cursors, and ions [98]. The neurovascular and neurometabolic coupling is, therefore, likely to have a direct effect on the permeability of $\mathrm{BBB}$ with respect to all these substances. The study of FUS-induced BBB permeabilization in conjunction with $\mathrm{AMRI}$ with a BOLD signal is challenging due to the difficulty of interpreting the BOLD signal itself. However, at the same time, the combination of these techniques may unlock the possibility of understanding the neurophysiological mechanisms involved in the neuron-to-BBB feedback.

The first study to employ fMRI to investigate neuromodulation induced by $\mathrm{BBB}$ permeabilization in rats was published by Chu et al. [99]. The authors measured permeabilization-related changes in somatosensory evoked potentials (SSEPs) and BOLD responses. Rats were sonicated (with APs of $0.30,0.55$, or $0.80 \mathrm{MPa}$ ) at the forelimb region in the left primary somatosensory cortex. fMRI acquisitions were performed in conjunction with forepaw electrical stimulations through a 7 Tesla Bruker BioSpec system (Bruker Corp., Billerica, MA) using a gradient-echo EPI sequence $(\mathrm{TR} / \mathrm{TE}=2,000 / 20 \mathrm{~ms}$, $\mathrm{FOV}=2.5 \times 2.5 \mathrm{~cm}$, slice thickness $=1 \mathrm{~mm}$ and matrix $=80$ $\times 80$ ). The authors found short-term suppression of SSEP for 
$<60$ min with an MI of 0.55 . Conversely, a higher MI induced suppression of SSEP amplitude for 7 days.

A similar study by Todd et al. [100] has shown that even safe levels of FUS BBB opening may affect the physiological processes generating the BOLD fMRI signal in rats. The study reported a reduction in functional connectivity of the targeted area with the surrounding brain regions. The authors first disrupted the BBB right primary somatosensory cortex hindlimb region (S1HL) through a US transducer working at $690 \mathrm{kHz}$, with $0.3 \mathrm{MPa}$ of AP (e.g., an MI of 0.4), and successively investigated BOLD signals and local functional connectivity changes. They employed a $2 \mathrm{D}$ single-shot gradient-echo EPI sequence (resolution $=0.5 \times 0.5 \times$ $1.0 \mathrm{~mm}^{3} ; 18$ slices with $0.2 \mathrm{~mm}$ slice gap; TR/TE $=1,500 / 18 \mathrm{~ms}$; $\mathrm{FA}=65^{\circ}$ ). In detail, this study observed a functional loss in the targeted region, which was detected by analyzing functional connectivity between anatomic regions, voxel-wise correlation maps calculated through seed-based correlation analysis and spatial patterns found from independent component analysis.

In 2019, two fMRI studies investigated functional loss due to FUS-induced BBB-permeabilization [25, 26]. In the first study, published by Todd et al. [26], the authors suggested that FUS-induced $\mathrm{BBB}$ permeabilization may cause changes in hemodynamic responses usually evoked by the application of external stimuli, in turn indicating that local alterations of neurovascular physiology accompany BBB disruption. In this study, FUS was applied along a $2 \times 2 \mathrm{~mm}$ square trajectory to ensure a homogenous $\mathrm{BBB}$ disruption in the right $\mathrm{S} 1$ region of rat brains $(10 \mathrm{~ms}$ bursts, $1 \mathrm{~Hz}$ repetition frequency, of $0.26 \mathrm{MPa}$ in the brain). fMRI data were acquired using a $2 \mathrm{D}$ single-shot gradient-echo EPI sequence [same parameters used in [100] both during electrical stimulation of the rat's hind paws and during a carbogen gas breathing challenge $\left(95 \% \mathrm{O}_{2}, 5 \% \mathrm{CO}_{2}\right.$; causing vasodilatory effects). The study showed that FUS-based BBB opening leads to a marked decrease in amplitude and duration of BOLD response in the target region in case of stimulusinduced neuronal activity. Surprisingly, local attenuation in BOLD signal in permeabilized regions of the brain was detected also during carbogen breathing, which is expected to yield and increase in the BOLD signal due to vasodilation [101]. The authors interpreted these results by hypothesizing that FUS$\mathrm{BBB}$ opening may cause a local change in brain neurovascular physiology which in turn may hinder the vascular response to local requests for increased blood flow, hence locally affecting the BOLD signal.

In the same year, these authors investigated how gammaaminobutyric acid (GABA) delivery through FUS-disrupted BBB can modulate brain activity in the primary somatosensory cortex of rats [25]. By acquiring functional MR images, they found that a combination of FUS-induced BBB permeabilization and GABA injections further reduces the BOLD signal response to the external stimuli (bilateral hind paw electrical stimulations) both in peak amplitude and in spatial extension. In this study, the authors used the same acoustic protocol as in [26] (MI = 0.4 ). fMRI data were acquired before and after GABA injection through a $2 \mathrm{D}$ single-shot gradient-echo EPI sequence with the same parameters used in $[26,100]$.

\section{MODELS DEPICTING DRUGS DISTRIBUTIONS AFTER BBB DISRUPTION}

Over the last few years, a growing number of studies have been performed to characterize and predict particle distribution within the brain after FUS-induced BBB permeabilization. A model based on DCE-MR imaging by Chai et al. [102] was able to describe FUS-MR-CA delivery to CNS. The model is capable of estimating the molecular penetration distribution in DCEMR images when molecules with different sizes (from 40 to 149 $\mathrm{kDa}$ ) are released into the brain by using different MIs. This model was validated on DCE-MRI acquisitions performed on rats after Gd-DTPA administration. MR images were acquired through a 7-Tesla MR scanner (Bruker Corp., Billerica, MA) (gradient-recall-echo sequence, TR/TE $=2.31 \mathrm{~ms} / 0.76 \mathrm{~ms}$, slice thickness $=0.8 \mathrm{~mm}$; slice number $=14$; matrix $=132 \times 192$, FA $=5 / 10 / 15 / 20 / 25 / 30^{\circ}$ ).

Relatedly, a numerical model by Conti et al. [71] was able to predict particle distributions in quantitative MR-CA concentrations maps for up to over $3 \mathrm{~h}$ after BBB disruption and molecule administration. This model, validated through animal experiments performed on a 7T MR scanner (Bruker Corp., Billerica, MA), takes into account several factors including US parameters (e.g., AP), particle size, blood pharmacokinetics (e.g., particles half-life and clearance rate), and molecular apparent diffusion coefficient, in turn depending on the tortuosity of the targeted region of the brain. The model is designed to be based on (CA)-maps calculated from repeated IR-FGE (Inversion Recovery Fast Gradient Echo) MRI acquisitions, which consist of a segmented series of FGE images acquired at different time points after magnetization inversion (TR1 $=5 \mathrm{~ms}, \mathrm{TE}=2.5 \mathrm{~ms}$, six segments, 60 inversion times (from 64 to $5,800 \mathrm{~ms}$ ), $\mathrm{FA}=5^{\circ}$, and resolution $=0.2 \times 0.2 \times 1 \mathrm{~mm}^{3}$ ).

A recent study by Valdez et al. [103] described a model able to characterize the distribution and diffusion of differentmolecular-weight dextran molecules within the brain within 20 min after administration. The model uses both T1-weighted MR-images and fluorescence imaging. MRI acquisitions were performed through a $7 \mathrm{~T}$ MRI system (Bruker Medical, Boston, MA) by using a spin-echo sequence (TR/TE $=400 / 9 \mathrm{~ms}$, a field of view $=1.92 \times 1.92$, matrix size $=128 \times 128$, slice thickness $=750 \mu \mathrm{m})$. In detail, this model considered diffusion over $20 \mathrm{~min}$ from continuously supplied point sources, which in turn means assuming that the concentration of dextran in the blood remains constant over the whole 20 min period. However, this model cannot predict MRCA distributions since CA concentrations vary within this experimental window [104].

Papers described in this section were the result of a PubMed search using the keywords MRI AND FUS AND BBB-opening, MRI AND FUS and BBB-opening, Diffusion AND FUS AND BBB-opening. Searches were executed on 15/01/2019. Details from cited papers which develop or employ models based on MRI acquisitions, able to depict particles distributions within the brain after FUS-induced $\mathrm{BBB}$ opening are presented in Table 3. 
TABLE 3 | Specifications of studies, included in this narrative review, using MR-CA administration to validate models able to depict particles distributions within the brain after FUS-induced BBB opening experiments.

\begin{tabular}{|c|c|c|c|c|c|}
\hline References & Model description & $\begin{array}{l}\text { Animal } \\
\text { species }\end{array}$ & MRI scanner & MRI sequence & MR-CA \\
\hline Chai et al. [102] & $\begin{array}{l}\text { Model able to describe molecular } \\
\text { penetration distribution in DCE-MR } \\
\text { images for different Mls }\end{array}$ & Rat & $7 \mathrm{~T}$ (Bruker) & $\begin{array}{l}\text { DCE T1-w (gradient-recall-echo sequence, } \\
\text { TR/TE }=2.31 / 0.76 \mathrm{~ms} \text {, slice thickness }=0.8 \mathrm{~mm} \text {; } \\
\text { slice number }=14 ; \text { matrix }=132 \times 192 \\
\left.\mathrm{FA}=5 / 10 / 15 / 20 / 25 / 30^{\circ}\right)\end{array}$ & Gd-DTPA \\
\hline Conti et al. [71] & $\begin{array}{l}\text { Model able to depict and predict } \\
\text { nanoparticles distributions after BBB } \\
\text { disruption for different US } \\
\text { parameters, particle size, blood } \\
\text { pharmacokinetics, and EES tortuosity }\end{array}$ & Rat & $7 \mathrm{~T}$ (Bruker) & $\begin{array}{l}(\mathrm{CA}) \text {-maps FGE }(\mathrm{TR} 1=5 \mathrm{~ms}, \mathrm{TR} 2=9 \mathrm{~s}, \\
\mathrm{TE}=2.5 \mathrm{~ms}, \text { six segments, } 60 \text { inversion times (from } \\
64 \text { to } 5,800 \mathrm{~ms}), \mathrm{FA}=5^{\circ}, \text { and Resolution }=0.2 \times \\
0.2 \times 1 \mathrm{~mm}^{3} \text { ) }\end{array}$ & $\begin{array}{l}\text { Gd-DOTA, } \\
\text { Gd-BOPTA, } \\
\text { Gd-DO3A-butrol }\end{array}$ \\
\hline Valdez et al. [103] & $\begin{array}{l}\text { Model able to characterize distribution } \\
\text { of different-molecular-weight dextran } \\
\text { molecules }\end{array}$ & Mice & $7 \mathrm{~T}$ (Bruker) & $\begin{array}{l}\text { T1 }-\mathrm{w} \text { SE }(\mathrm{TR} / \mathrm{TE}=400 / 9 \mathrm{~ms} \text {, field of view }=1.92 \times \\
1.92, \text { matrix size }=128 \times 128, \text { slice } \\
\text { thickness }=750 \mathrm{~mm})\end{array}$ & Gd-BOPTA \\
\hline
\end{tabular}

\section{MRI PROTOCOLS IN FUS-BBB OPENING IN HUMAN SUBJECTS}

As discussed previously, MR-based technologies and acquisitions can be used for enabling BBB-permeabilization experiments. In this section, we present a summary of the MR-imaging methods suitable to guide and monitor FUS-induced $\mathrm{BBB}$ disruption in humans. In 2018, Lipsman et al. [32] described the results of a clinical trial that treated five Alzheimer's Disease patients through LIFUS application for BBB opening. The FUS device consisted of a transducer with 1,024 elements driven at $220 \mathrm{kHz}$ (ExAblate Neuro; INSIGHTEC Haifa, Israel) installed in a 3T MRI scanner (Signa MR750; GE Healthcare, Milwaukee, WI). Before treatment, each subject underwent the same MRI protocol composed by a T1-, T2- (fast spinecho), and $\mathrm{T}^{*}$ - (gradient echo) weighted images to identify target regions. After the administration of $4 \mu \mathrm{l} / \mathrm{kg}$ of UCA (Definity ${ }^{\circledR}$ ), LIFUS was applied while monitoring temperature through MR thermometry. The US was applied twice a month within a rectangular volume $\left(10 \times 10 \times 7 \mathrm{~mm}^{3}\right)$ along a square trajectory. During sonication, acoustic parameters were limited by the clinical device hardware to avoid microbubbles inertial cavitation. Acoustic powers ranged between 2.5 and $7.5 \mathrm{~W}$. After sonication, the administration of a gadolinium-chelate was followed by a T1-weighed MRI acquisition. Figure 5A shows exemplar T1-weighted images obtain before, immediately after, and $24 \mathrm{~h}$ after sonication in one subject treated by Lipsman et al. [32]. These images were obtained after MR-CA administration. While contrast is enhanced right after BBB disruption, no CA extravasation is revealed $24 \mathrm{~h}$ after sonication, hence pointing to BBB closure.

In 2019, the same group investigated resting-state (i.e., task-free) functional connectivity changes in the bilateral frontoparietal network induced in Alzheimer's Disease patients by FUS-induced $\mathrm{BBB}$ opening, during 1 month after the procedure [74]. These authors found a transient connectivity decrease in the network, which was then restored at $24 \mathrm{~h}$ after treatment. Resting-state fMRI (rs-fMRI) acquisitions were performed through a 3-T MRI (Signa MR750; GE Healthcare,
Milwaukee, WI) by using 200 temporal volumes of 40 slices (3.6 mm thick), $\mathrm{TE} \backslash \mathrm{TR}=30 \backslash 2,400 \mathrm{~ms}$.

Abrahao et al. [75] also used fMRI acquisitions during a motor task to test the feasibility and safety of LIFUS-induced BBB permeabilization in four Amyotrophic Lateral Sclerosis (ALS) patients in lag and hand control regions in the primary motor cortex (see Figure 5B). The fMRI data were employed to specifically target the US to the primary motor cortex (as shown in Figure 5B). MRI acquisitions were performed through a 3T scanner (Signa MR750; GE Healthcare, Milwaukee, Wis.) with an eight-channel head receiver coil. 3D anatomical images were acquired through an inversion recovery prepared fast spoiled gradient echo (IR-FSPGR) $(\mathrm{TE} / \mathrm{TR}=2.94 / 7.65 \mathrm{~ms}$, matrix size $=$ $265 \times 265$, slice thickness $=1 \mathrm{~mm}$ ). fMRI scans were performed by acquiring 130 temporal volumes of 36 slices with $4 \mathrm{~mm}$ thickness, TR/TE $=2,000 / 30 \mathrm{~ms} ; \mathrm{FA}=70^{\circ}$, matrix size $=64 \times$ 64) during a motor task of $4 \mathrm{~min} 28 \mathrm{~s}$ duration. BBB opening was targeted to the arm or leg regions as mapped by task fMRI. The authors used the $220 \mathrm{kHz}$ ExAblate Neuro 4000 system type 2.0 with 1,024 ultrasound transducers coupled to the 3-Tesla MRI.

All articles presented in this section were the results of a PubMed search performed using the keywords MRI AND FUS AND BBB-opening AND patients, MRI AND FUS AND BBB-opening AND Alzheimer's; MRI AND Ultrasound AND BBB-opening AND Parkinson's Disease Dementia; MRI AND ultrasound AND BBB AND Amyotrophic Lateral Sclerosis. Searches were executed on 15/01/2019.

\section{FUTURE PERSPECTIVES IN MR-GUIDED BBB OPENING}

FUS-mediated BBB disruption has been demonstrated to be capable of delivering a number of drugs and other potential therapeutic substances to the brain. The development of this technique has been closely dependent on the availability of MRI technology for the treatment planning, execution, and evaluation. In this review, we have summarized the main MR methods employed to guide FUS before, during and after 


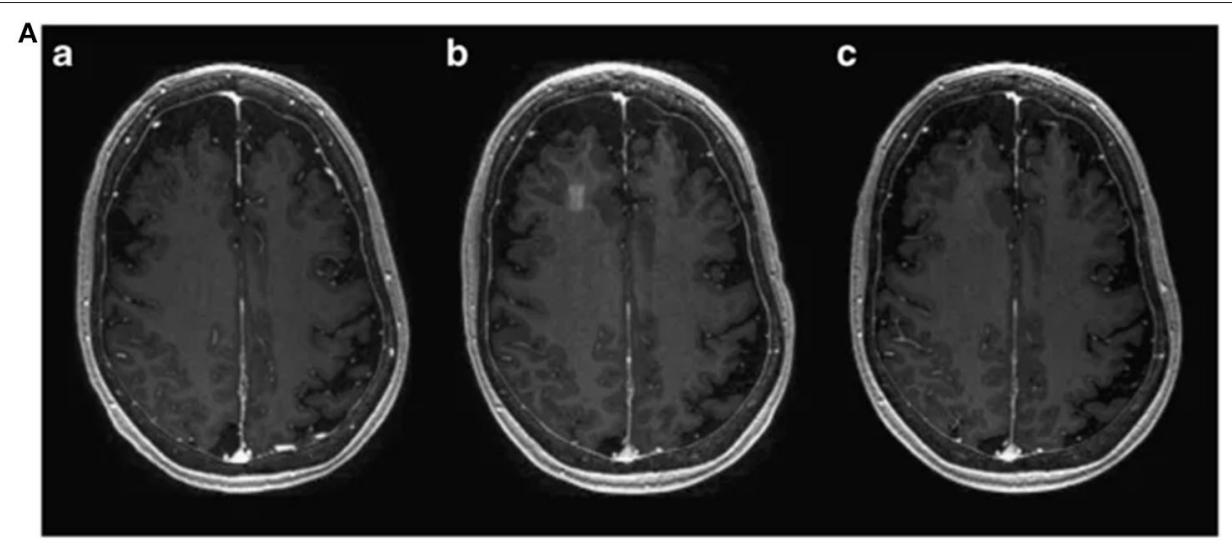

B

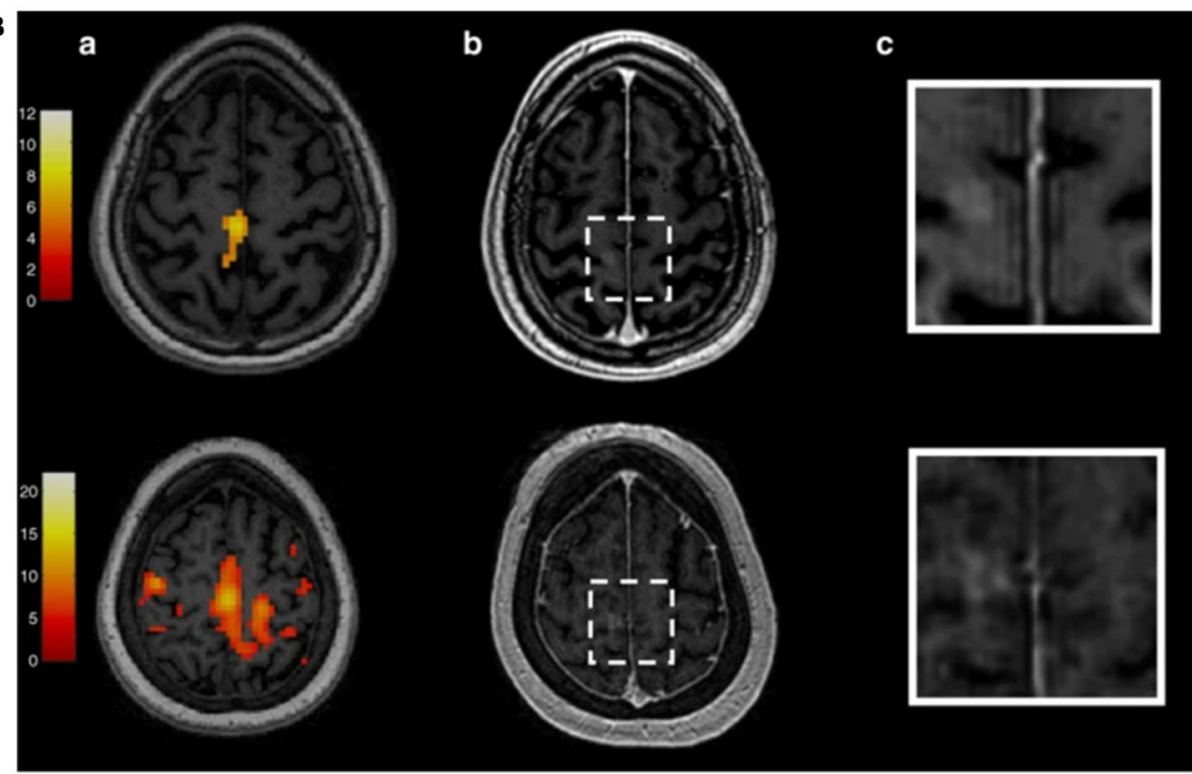

FIGURE 5 | (A): Contrast-enhanced T1-weighed MR images obtained before (a), immediately (b), and $24 \mathrm{~h}$ (c) after BBB opening [32]. Figure reproduced with permission from [32]. (B): fMRI images used by [75] to specifically target the US to the primary motor cortex in a human subject. BBB opening has been then evaluated through the acquisition of Contrast-enhanced T1-weighed MR images (b,c). Figure reproduced with permission from [75].

the $\mathrm{BBB}$ permeabilization protocol, demonstrating that MRguided focused ultrasound is a unique, exciting and effective technique able to induce brain changes and drug delivery in the brain in a non-invasive, temporally and spatially controlled manner.

MRI, and specifically MR elastography, has often been used for improving brain targeting based on tissue displacement monitoring [38, 41, 42]. However, neuronavigationguided ultrasound [105] can be a valid alternative for all procedures performed in-scanner. This procedure relies on in silico pre-planning (targeting) based on computed tomography, MRI, and neuronavigation systems. This procedure can reduce costs and improve comfort for patients, especially in cases involving critical care patients or repeated sessions.

The evaluation of $\mathrm{BBB}$ opening and closure dynamics is commonly performed by analyzing T1-weighted MR images and parametric T1-maps and requires the administration of an MRI CA. The most common choice is a gadolinium chelate. However, the accumulation of MR-CAs may lead to adverse reactions, especially in patients with a history of asthma, allergies, and renal insufficiency and when injections are performed at faster rates [106]. For this reason, minimizing the use of Gd-CAs through the development of different MRI strategies for the evaluation of $\mathrm{BBB}$ opening dynamics and brain changes is advisable to optimize treatment and ensure patient safety. For example, a local increase of the EES [71, 107] induced by FUS-mediated BBB disruption could pave the way for the evaluation of BBB opening using diffusion MRI or multimodal MRI acquisitions, which would allow more in-depth characterization of microstructural brain changes [108, 109].

MRI evaluation of tissue damage can reveal blood extravasation and edema formation that may occur when inadequate acoustic parameters are employed. This is commonly 
performed using T2- and T2*-weighted images. However, the procedure can be improved by combining techniques to detect harmful treatment conditions in real-time with feedback control prior to causing damages. In this context, cavitation monitoring has been used to identify potentially harmful microbubble activity [110]. For high-pressure levels, microbubbles engage in strong oscillations, increase in size, and deform in shape. This eventually leads to collapses, which in turn release strong jets. Cavitation activity can be acoustically monitored using a second transducer (passive acoustic detector or an imaging probe) coupled to the patient's head. The scattered acoustic signal emitted by the cavitating microbubbles reveals the signature of each of the processes involved in the cavitation activity (stable or inertial cavitation). Therefore, MRI and cavitation detectionbased feedback techniques [29, 66, 111] are complementary in the efficacy of effect monitoring and for evaluating brain integrity and local drug release.

As mentioned, functional MRI has been used for the evaluation of both functional changes and neuromodulatory effects induced by sonication [99, 100, 112]. In future studies, this technique may also be used to e.g., evaluate improvements of cognitive function induced by ultrasound-mediated blood-brain

\section{REFERENCES}

1. Konofagou EE, Tung Y-S, Choi J, Deffieux T, Baseri B, Vlachos F. Ultrasound-induced blood-brain barrier opening. Curr Pharm Biotechnol. (2012) 13:1332-45. doi: 10.2174/138920112800624364

2. Burgess A, Shah K, Hough O, Hynynen K. Focused ultrasound-mediated drug delivery through the blood-brain barrier. Expert Rev Neurother. (2015) 15:477-91. doi: 10.1586/14737175.2015.1028369

3. Alonso A. Ultrasound-induced blood-brain barrier opening for drug delivery. Front Neurol Neurosci. (2015) 36:106-15. doi: 10.1159/000366242

4. Poon C, McMahon D, Hynynen K. Noninvasive and targeted delivery of therapeutics to the brain using focused ultrasound. Neuropharmacology. (2017) 120:20-37. doi: 10.1016/j.neuropharm.2016.02.014

5. Bellavance M-A, Blanchette M, Fortin D. Recent advances in blood-brain barrier disruption as a CNS delivery strategy. AAPS J. (2008) 10:166-77. doi: 10.1208/s12248-008-9018-7

6. Konofagou EE. Optimization of the ultrasound-induced blood-brain barrier opening. Theranostics. (2012) 2:1223-37. doi: 10.7150/thno. 5576

7. Timbie KF, Mead BP, Price RJ. Drug and gene delivery across the bloodbrain barrier with focused ultrasound. J Control Release. (2015) 219:61-75. doi: 10.1016/j.jconrel.2015.08.059

8. Fisher DG, Price RJ. Recent advances in the use of focused ultrasound for magnetic resonance image-guided therapeutic nanoparticle delivery to the central nervous system. Front Pharmacol. (2019) 10:1348. doi: 10.3389/fphar.2019.01348

9. Peruzzi G, Sinibaldi G, Silvani G, Ruocco G, Casciola CM. Perspectives on cavitation enhanced endothelial layer permeability. Colloids Surf B Biointerfaces. (2018) 168:83-93. doi: 10.1016/j.colsurfb.2018.02.027

10. Chen K-T, Wei K-C, Liu H-L. Theranostic strategy of focused ultrasound induced blood-brain barrier opening for CNS disease treatment. Front Pharmacol. (2019) 10:86. doi: 10.3389/fphar.2019.00086

11. Hynynen K, McDannold N, Vykhodtseva N, Jolesz FA. Non-invasive opening of BBB by focused ultrasound. Acta Neurochir Suppl. (2003) 86:5558. doi: 10.1007/978-3-7091-0651-8_113

12. Choi JJ, Selert K, Gao Z, Samiotaki G, Baseri B, Konofagou EE. Noninvasive and localized blood-brain barrier disruption using focused ultrasound can be achieved at short pulse lengths and low pulse repetition frequencies. barrier opening in Alzheimer's Disease with and without the delivery of neurotrophic factors [113]. Also, since it has been recently shown that FUS exposure may induce reactive gliosis [114], which in turn can inhibit neuroplasticity and regeneration [115], future works may leverage fMRI acquisitions to noninvasively evaluate these effects.

While it is well-known that FUS application affects EES by enlarging the extracellular volume fraction [71, 107], so far the effects of sonication on molecular pseudo-diffusion (and hence on the velocity of water within the vessels and its diffusion within the blood) have not been investigated. Future studies involving intravoxel incoherent motion (IVIM) acquisitions [116] right after FUS-induced BBB opening may help in eludidatig whether FUS application affects not only diffusion within the EES but also pseudo-diffusion within blood vessels.

\section{AUTHOR CONTRIBUTIONS}

AC, HK, and NT contributed to manuscript drafting and editing. All authors contributed to manuscript revision, validation, and approved the final draft for submission.

J Cereb Blood Flow Metab. (2011) 31:725-37. doi: 10.1038/jcbfm.2 010.155

13. Chen $\mathrm{H}$, Konofagou EE. The size of blood-brain barrier opening induced by focused ultrasound is dictated by the acoustic pressure. J Cereb Blood Flow Metab. (2014) 34:1197-204. doi: 10.1038/jcbfm.2014.71

14. Marty B, Larrat B, Van Landeghem M, Robic C, Robert P, Port M, et al. Dynamic study of blood-brain barrier closure after its disruption using ultrasound: a quantitative analysis. J Cereb Blood Flow Metab. (2012) 32:1948-58. doi: 10.1038/jcbfm.2012.100

15. Souza RMDCE, da Silva ICS, Delgado ABT, da Silva PHV, Costa VRX. Focused ultrasound and Alzheimer's disease a systematic review. Dement Neuropsychol. (2018) 12:353-9. doi: 10.1590/1980-57642018dn12-040003

16. Hsu P-H, Lin Y-T, Chung Y-H, Lin K-J, Yang L-Y, Yen T-C, et al. Focused ultrasound-induced blood-brain barrier opening enhances GSK-3 inhibitor delivery for amyloid-beta plaque reduction. Sci Rep. (2018) 8:1-9. doi: 10.1038/s41598-018-31071-8

17. Miller DB, O'Callaghan JP. New horizons for focused ultrasound (FUS)therapeutic applications in neurodegenerative diseases. Metabolism. (2017) 69S:S3-7. doi: 10.1016/j.metabol.2017.01.012

18. Fan C-H, Yeh C-K. Microbubble-enhanced focused ultrasound-induced blood-brain barrier opening for local and transient drug delivery in central nervous system disease. J Med Ultrasound. (2014) 22:183-93. doi: 10.1016/j.jmu.2014.11.001

19. Mainprize T, Lipsman N, Huang Y, Meng Y, Bethune A, Ironside S, et al. Blood-brain barrier opening in primary brain tumors with non-invasive MRguided focused ultrasound: a clinical safety and feasibility study. Sci Rep. (2019) 9:1-7. doi: 10.1038/s41598-018-36340-0

20. Conti A, Gerstenmayer M, Geffroy F, Tillement O, Lux F, Mériaux S, et al. Comparison of single spot and volume ultrasound sonications for efficient nanoparticle delivery to glioblastoma model in rats. In: 2017 IEEE International Ultrasonics Symposium (IUS). Washington, DC (2017). doi: 10.1109/ULTSYM.2017.8092481

21. Hynynen K, McDannold N, Vykhodtseva N, Jolesz FA. Noninvasive MR imaging-guided focal opening of the blood-brain barrier in rabbits. Radiology. (2001) 220:640-6. doi: 10.1148/radiol.2202001804

22. Mériaux S, Conti A, Larrat B. Assessing diffusion in the extra-cellular space of brain tissue by dynamic MRI mapping of contrast agent concentrations. Front Phys. (2018) 6:38. doi: 10.3389/fphy.2018.00038 
23. McDannold N, King RL, Hynynen K. MRI monitoring of heating produced by ultrasound absorption in the skull: in vivo study in pigs. Magn Reson Med. (2004) 51:1061-5. doi: 10.1002/mrm.20043

24. Liu H-L, Wai Y-Y, Chen W-S, Chen J-C, Hsu P-H, Wu X-Y, et al. Hemorrhage detection during focused-ultrasound induced blood-brain-barrier opening by using susceptibility-weighted magnetic resonance imaging. Ultrasound Med Biol. (2008) 34:598-606. doi: 10.1016/j.ultrasmedbio.2008.01.011

25. Todd N, Zhang Y, Power C, Becerra L, Borsook D, Livingstone M, et al. Modulation of brain function by targeted delivery of GABA through the disrupted blood-brain barrier. NeuroImage. (2019) 189:267-75. doi: 10.1016/j.neuroimage.2019.01.037

26. Todd N, Zhang Y, Livingstone M, Borsook D, McDannold N. The neurovascular response is attenuated by focused ultrasound-mediated disruption of the blood-brain barrier. Neuroimage. (2019) 201:116010. doi: 10.1016/j.neuroimage.2019.116010

27. Kamimura HAS, Conti A, Toschi N, Konofagou EE. Ultrasound neuromodulation: mechanisms and the potential of multimodal stimulation for neuronal function assessment. Front Phys. (2020) 8:150. doi: 10.3389/fphy.2020.00150

28. Magnin R, Rabusseau F, Salabartan F, Mériaux S, Aubry J-F, Le Bihan D, et al. Magnetic resonance-guided motorized transcranial ultrasound system for blood-brain barrier permeabilization along arbitrary trajectories in rodents. J Ther Ultrasound. (2015) 3:22. doi: 10.1186/s40349-015-0044-5

29. Kamimura HA, Flament J, Valette J, Cafarelli A, Aron Badin R, Hantraye P, et al. Feedback control of microbubble cavitation for ultrasound-mediated blood-brain barrier disruption in non-human primates under magnetic resonance guidance. J Cereb Blood Flow Metab. (2019) 39:1191-203. doi: $10.1177 / 0271678 X 17753514$

30. Hynynen K, Clement GT, McDannold N, Vykhodtseva N, King R, White PJ, et al. 500-element ultrasound phased array system for noninvasive focal surgery of the brain: a preliminary rabbit study with ex vivo human skulls. Magn Reson Med. (2004) 52:100-7. doi: 10.1002/mrm.20118

31. Ghanouni P, Pauly KB, Elias WJ, Henderson J, Sheehan J, Monteith $S$, et al. Transcranial MR-guided focused ultrasound: a review of the technology and neuro applications. AJR Am J Roentgenol. (2015) 205:150-9. doi: 10.2214/AJR.14.13632

32. Lipsman N, Meng Y, Bethune AJ, Huang Y, Lam B, Masellis M, et al. Bloodbrain barrier opening in Alzheimer's disease using MR-guided focused ultrasound. Nat Commun. (2018) 9:1-8. doi: 10.1038/s41467-018-04529-6

33. Goldwirt L, Canney M, Horodyckid C, Poupon J, Mourah S, Vignot A, et al. Enhanced brain distribution of carboplatin in a primate model after bloodbrain barrier disruption using an implantable ultrasound device. Cancer Chemother Pharmacol. (2016) 77:211-6. doi: 10.1007/s00280-015-2930-5

34. Horodyckid C, Canney M, Vignot A, Boisgard R, Drier A, Huberfeld G, et al. Safe long-term repeated disruption of the blood-brain barrier using an implantable ultrasound device: a multiparametric study in a primate model. J Neurosurg. (2017) 126:1351-61. doi: 10.3171/2016.3.JNS151635

35. Dréan A, Lemaire N, Bouchoux G, Goldwirt L, Canney M, Goli L, et al. Temporary blood-brain barrier disruption by low intensity pulsed ultrasound increases carboplatin delivery and efficacy in preclinical models of glioblastoma. J Neurooncol. (2019) 144:33-41. doi: 10.1007/s11060-019-03204-0

36. Carpentier A, Canney M, Vignot A, Reina V, Beccaria K, Horodyckid C, et al. Clinical trial of blood-brain barrier disruption by pulsed ultrasound. Sci Transl Med. (2016) 8:343re2. doi: 10.1126/scitranslmed.aaf6086

37. Arvanitis CD, Ferraro GB, Jain RK. The blood-brain barrier and bloodtumour barrier in brain tumours and metastases. Nat Rev Cancer. (2020) 20:26-41. doi: 10.1038/s41568-019-0205-x

38. Muthupillai R, Lomas DJ, Rossman PJ, Greenleaf JF, Manduca A, Ehman RL. Magnetic resonance elastography by direct visualization of propagating acoustic strain waves. Science. (1995) 269:1854-7. doi: 10.1126/science.7569924

39. Sack I, McGowan CK, Samani A, Luginbuhl C, Oakden W, Plewes DB. Observation of nonlinear shear wave propagation using magnetic resonance elastography. Magn Reson Med. (2004) 52:842-50. doi: 10.1002/mrm.20238

40. Souchon R, Salomir R, Beuf O, Milot L, Grenier D, Lyonnet D, et al. Transient MR elastography (t-MRE) using ultrasound radiation force: theory, safety, and initial experiments in vitro. Magn Reson Med. (2008) 60:871-81. doi: $10.1002 / \mathrm{mrm} .21718$

41. McDannold N, Maier SE. Magnetic resonance acoustic radiation force imaging. Med Phys. (2008) 35:3748-58. doi: 10.1118/1.2956712

42. Larrat B, Pernot M, Aubry J-F, Dervishi E, Sinkus R, Seilhean D, et al. MRguided transcranial brain HIFU in small animal models. Phys Med Biol. (2009) 55:365-88. doi: 10.1088/0031-9155/55/2/003

43. Kaye EA, Pauly KB. Adapting MRI acoustic radiation force imaging for in vivo human brain focused ultrasound applications. Magn Reson Med. (2013) 69:724-33. doi: 10.1002/mrm.24308

44. Wu C-H, Liu H-L, Ho C-T, Hsu P-H, Fan C-H, Yeh C-K, et al. Monitoring of acoustic cavitation in microbubble-presented focused ultrasound exposure using gradient-echo MRI. J Magn Reson Imaging. (2020) 51:311-8. doi: 10.1002/jmri.26801

45. Hynynen K, McDannold N, Sheikov NA, Jolesz FA, Vykhodtseva N. Local and reversible blood-brain barrier disruption by noninvasive focused ultrasound at frequencies suitable for trans-skull sonications. Neuroimage. (2005) 24:12-20. doi: 10.1016/j.neuroimage.2004.06.046

46. Choi JJ, Pernot M, Small SA, Konofagou EE. Feasibility of transcranial, localized drug-delivery in the brain of Alzheimer's-model mice using focused ultrasound. In: IEEE Ultrasonics Symposium. Rotterdam (2005). p. 988-91.

47. Choi JJ, Pernot M, Small SA, Konofagou EE. Noninvasive, transcranial and localized opening of the blood-brain barrier using focused ultrasound in mice. Ultrasound Med Biol. (2007) 33:95-104. doi: 10.1016/j.ultrasmedbio.2006.07.018

48. McDannold N, Vykhodtseva N, Hynynen K. Effects of acoustic parameters and ultrasound contrast agent dose on focused-ultrasound induced blood-brain barrier disruption. Ultrasound Med Biol. (2008) 34:930-7. doi: 10.1016/j.ultrasmedbio.2007.11.009

49. Choi JJ, Selert K, Vlachos F, Wong A, Konofagou EE. Noninvasive and localized neuronal delivery using short ultrasonic pulses and microbubbles. Proc Natl Acad Sci USA. (2011) 108:16539-44. doi: 10.1073/pnas.1105116108

50. O’Reilly MA, Waspe AC, Ganguly M, Hynynen K. Focused-ultrasound disruption of the blood-brain barrier using closely-timed short pulses: influence of sonication parameters and injection rate. Ultrasound Med Biol. (2011) 37:587-94. doi: 10.1016/j.ultrasmedbio.2011.01.008

51. Kamimura H, Wang S, Wu S-Y, Karakatsani M, Acosta C, Carneiro A, et al. Chirp- and random-based coded ultrasonic excitation for localized blood-brain barrier opening. Phys Med Biol. (2015) 60:7695-712. doi: 10.1088/0031-9155/60/19/7695

52. Tung Y-S, Vlachos F, Choi JJ, Deffieux T, Selert K, Konofagou EE. In vivo transcranial cavitation threshold detection during ultrasound-induced blood-brain barrier opening in mice. Phys Med Biol. (2010) 55:6141-55. doi: 10.1088/0031-9155/55/20/007

53. Baseri B, Choi JJ, Tung Y-S, Konofagou EE. Multi-modality safety assessment of blood-brain barrier opening using focused ultrasound and definity microbubbles: a short-term study. Ultrasound Med Biol. (2010) 36:1445-59. doi: 10.1016/j.ultrasmedbio.2010.06.005

54. Marquet F, Tung Y-S, Teichert T, Ferrera VP, Konofagou EE. Noninvasive, transient and selective blood-brain barrier opening in non-human primates in vivo. PLoS ONE. (2011) 6:e22598. doi: 10.1371/journal.pone.0022598

55. Aryal M, Papademetriou I, Zhang Y-Z, Power C, McDannold N, Porter T. MRI monitoring and quantification of ultrasound-mediated delivery of liposomes dually labeled with gadolinium and fluorophore through the blood-brain barrier. Ultrasound Med Biol. (2019) 45:1733-42. doi: 10.1016/j.ultrasmedbio.2019.02.024

56. Brix G, Schreiber W, Hoffmann U, Gückel F, Hawighorst H, Knopp MV. Methodological approaches to quantitative evaluation of microcirculation in tissues with dynamic magnetic resonance tomography. Radiologe. (1997) 37:470-80. doi: 10.1007/s001170050241

57. Essig M, Shiroishi MS, Nguyen TB, Saake M, Provenzale JM, Enterline D, et al. Perfusion MRI: the five most frequently asked technical questions. Am J Roentgenol. (2013) 200:24-34. doi: 10.2214/AJR.12.9543

58. Tofts PS, Kermode AG. Measurement of the blood-brain barrier permeability and leakage space using dynamic MR imaging. 1. Fundamental concepts. Magn Reson Med. (1991) 17:357-67. doi: $10.1002 / \mathrm{mrm} .1910170208$ 
59. Tofts PS, Brix G, Buckley DL, Evelhoch JL, Henderson E, Knopp MV, et al. Estimating kinetic parameters from dynamic contrast-enhanced $\mathrm{T}(1)$-weighted MRI of a diffusable tracer: standardized quantities and symbols. J Magn Reson Imaging. (1999) 10:223-32. doi: 10.1002/(sici)15222586(199909)10:3<223::aid-jmri2>3.0.co;2-s

60. Brix G, Semmler W, Port R, Schad LR, Layer G, Lorenz WJ. Pharmacokinetic parameters in CNS Gd-DTPA enhanced MR imaging. J Comput Assist Tomogr. (1991) 15:621-8. doi: 10.1097/00004728-199107000-00018

61. Vlachos F, Tung Y-S, Konofagou E. Permeability dependence study of the focused ultrasound-induced blood-brain barrier opening at distinct pressures and microbubble diameters using DCE-MRI. Magn Reson Med. (2011) 66:821-30. doi: 10.1002/mrm.22848

62. Chai W-Y, Chu P-C, Tsai M-Y, Lin Y-C, Wang J-J, Wei K-C, et al. Magnetic-resonance imaging for kinetic analysis of permeability changes during focused ultrasound-induced blood-brain barrier opening and brain drug delivery. J Control Release. (2014) 192:1-9. doi: 10.1016/j.jconrel.201 4.06 .023

63. Wei K-C, Tsai H-C, Lu Y-J, Yang H-W, Hua M-Y, Wu M-F, et al. Neuronavigation-guided focused ultrasound-induced blood-brain barrier opening: a preliminary study in swine. Am J Neuroradiol. (2013) 34:115-20. doi: 10.3174/ajnr.A3150

64. Li KL, Zhu XP, Waterton J, Jackson A. Improved 3D quantitative mapping of blood volume and endothelial permeability in brain tumors. J Magn Reson Imaging. (2000) 12:347-57. doi: 10.1002/1522-2586(200008)12:2<347::AIDJMRI19>3.0.CO;2-7

65. Fan C-H, Lin W-H, Ting C-Y, Chai W-Y, Yen T-C, Liu H-L, et al. Contrastenhanced ultrasound imaging for the detection of focused ultrasoundinduced blood-brain barrier opening. Theranostics. (2014) 4:1014-25. doi: $10.7150 /$ thno. 9575

66. Sun T, Samiotaki G, Wang S, Acosta CAO, Chen CC, Konofagou EE. Acoustic cavitation-based monitoring of the reversibility and permeability of ultrasound-induced blood-brain barrier opening. Phys Med Biol. (2015) 60:9079-94. doi: 10.1088/0031-9155/60/23/9079

67. Chu P-C, Chai W-Y, Tsai C-H, Kang S-T, Yeh C-K, Liu H-L. Focused ultrasound-induced blood-brain barrier opening: association with mechanical index and cavitation index analyzed by dynamic contrast-enhanced magnetic-resonance imaging. Sci Rep. (2016) 6:33264. doi: $10.1038 /$ srep33264

68. Wu S-K, Chu P-C, Chai W-Y, Kang S-T, Tsai C-H, Fan C-H, et al. Characterization of different microbubbles in assisting focused ultrasound-induced blood-brain barrier opening. Sci Rep. (2017) 7:46689. doi: 10.1038/srep46689

69. Yoon K, Lee W, Chen E, Lee JE, Croce P, Cammalleri A, et al. Localized blood-brain barrier opening in ovine model using image-guided transcranial focused ultrasound. Ultrasound Med Biol. (2019) 45:2391-404. doi: 10.1016/j.ultrasmedbio.2019.05.023

70. Conti A, Magnin R, Gerstenmayer M, Lux F, Tillement O, Mériaux S, et al. Characterization of the diffusion process of different gadolinium-based nanoparticles within the brain tissue after ultrasound induced blood-brain barrier permeabilization. In: 2016 IEEE International Ultrasonics Symposium (IUS). Tours (2016). p. 1-4. doi: 10.1109/ULTSYM.2016.7728773

71. Conti A, Magnin R, Gerstenmayer M, Tsapis N, Dumont E, Tillement O, et al. Empirical and theoretical characterization of the diffusion process of different gadolinium-based nanoparticles within the brain tissue after ultrasound-induced permeabilization of the blood-brain barrier. Contrast Media Mol Imaging. (2019) 2019:6341545. doi: 10.1155/2019/6341545

72. Samiotaki G, Karakatsani ME, Buch A, Papadopoulos S, Wu SY, Jambawalikar S, et al. Pharmacokinetic analysis and drug delivery efficiency of the focused ultrasound-induced blood-brain barrier opening in non-human primates. Magn Reson Imaging. (2017) 37:273-81. doi: 10.1016/j.mri.2016.11.023

73. Karakatsani MEM, Samiotaki GM, Downs ME, Ferrera VP, Konofagou EE. Targeting effects on the volume of the focused ultrasoundinduced blood-brain barrier opening in nonhuman primates in vivo. IEEE Trans Ultrason Ferroelectr Freq Control. (2017) 64:798-810. doi: 10.1109/TUFFC.2017.2681695

74. Meng Y, MacIntosh BJ, Shirzadi Z, Kiss A, Bethune A, Heyn C, et al. Resting state functional connectivity changes after MR-guided focused ultrasound mediated blood-brain barrier opening in patients with Alzheimer's disease. Neuroimage. (2019) 200:275-80. doi: 10.1016/j.neuroimage.2019.06.060

75. Abrahao A, Meng Y, Llinas M, Huang Y, Hamani C, Mainprize T, et al. First-in-human trial of blood-brain barrier opening in amyotrophic lateral sclerosis using MR-guided focused ultrasound. Nat Commun. (2019) 10:1-9. doi: 10.1038/s41467-019-12426-9

76. Yang F-Y, Liu S-H, Ho F-M, Chang C-H. Effect of ultrasound contrast agent dose on the duration of focused-ultrasound-induced blood-brain barrier disruption. J Acoust Soc Am. (2009) 126:3344-9. doi: 10.1121/1.3242376

77. Yang F-Y, Horng S-C, Lin Y-S, Kao Y-H. Association between contrastenhanced $\mathrm{MR}$ images and blood-brain barrier disruption following transcranial focused ultrasound. J Magn Reson Imaging. (2010) 32:593-9. doi: 10.1002/jmri.22297

78. Samiotaki G, Vlachos F, Tung Y-S, Konofagou EE. A quantitative pressure and microbubble-size dependence study of focused ultrasound-induced blood-brain barrier opening reversibility in vivo using MRI. Magn Reson Med. (2012) 67:769-77. doi: 10.1002/mrm.23063

79. Samiotaki G, Konofagou EE. Dependence of the reversibility of focusedultrasound-induced blood-brain barrier opening on pressure and pulse length in vivo. IEEE Trans Ultrason Ferroelectr Freq Control. (2013) 60:225765. doi: 10.1109/TUFFC.2013.6644731

80. Conti A, Mériaux S, Larrat B. About the marty model of blood-brain barrier closure after its disruption using focused ultrasound. Phys Med Biol. (2019) 64:14NT02. doi: 10.1088/1361-6560/ab259d

81. Lynn JG, Zwemer RL, Chick AJ, Miller AE. A new method for the generation and use of focused ultrasound in experimental biology. J Gen Physiol. (1942) 26:179-93. doi: 10.1085/jgp.26.2.179

82. Chen Y, Kateb B, Kateb B. Neurophotonics and Brain Mapping. Boca Raton, FL: CRC Press (2017). doi: 10.1201/9781315373058

83. Fry WJ. Intense ultrasound in investigations of the central nervous system. Adv Biol Med Phys. (1958) 6:281-348. doi: 10.1016/B978-1-4832-3112-9.50012-8

84. Ishihara Y, Calderon A, Watanabe H, Okamoto K, Suzuki Y, Kuroda K, et al. A precise and fast temperature mapping using water proton chemical shift. Magn Reson Med. (1995) 34:814-23. doi: 10.1002/mrm.1910340606

85. Huang Y, Alkins R, Schwartz ML, Hynynen K. Opening the blood-brain barrier with MR imaging-guided focused ultrasound: preclinical testing on a trans-human skull porcine model. Radiology. (2016) 282:123-30. doi: 10.1148/radiol.2016152154

86. Song K-H, Harvey BK, Borden MA. State-of-the-art of microbubbleassisted blood-brain barrier disruption. Theranostics. (2018) 8:4393-408. doi: 10.7150/thno.26869

87. Grossman RI, Gomori JM, Goldberg HI, Hackney DB, Atlas SW, Kemp SS, et al. MR imaging of hemorrhagic conditions of the head and neck. Radiographics. (1988) 8:441-54. doi: 10.1148/radiographics.8.3.33 80990

88. Ho M-L, Rojas R, Eisenberg RL. Cerebral edema. Am J Roentgenol. (2012) 199:W258-73. doi: 10.2214/AJR.11.8081

89. Greenberg SM, Vernooij MW, Cordonnier C, Viswanathan A, Salman RA-S, Warach S, et al. Cerebral microbleeds: a field guide to their detection and interpretation. Lancet Neurol. (2009) 8:165-74. doi: 10.1016/S1474-4422(09)70013-4

90. Fan C-H, Liu H-L, Ting C-Y, Lee Y-H, Huang C-Y, Ma Y-J, et al. Submicron-bubble-enhanced focused ultrasound for blood-brain barrier disruption and improved CNS drug delivery. PLoS ONE. (2014) 9:e96327. doi: 10.1371/journal.pone.0096327

91. Wu S-Y, Tung Y-S, Marquet F, Downs ME, Sanchez CS, Chen CC, et al. Transcranial cavitation detection in primates during blood-brain barrier opening-a performance assessment study. IEEE Trans Ultrason Ferroelectr Freq Control. (2014) 61:966-78. doi: 10.1109/TUFFC.2014. 2992

92. Liu H-L, Hsu P-H, Chu P-C, Wai Y-Y, Chen J-C, Shen C-R, et al. Magnetic resonance imaging enhanced by superparamagnetic iron oxide particles: usefulness for distinguishing between focused ultrasound-induced bloodbrain barrier disruption and brain hemorrhage. J Magn Reson Imaging. (2009) 29:31-8. doi: 10.1002/jmri.21599

93. Jones RM, Deng L, Leung K, McMahon D, O’Reilly MA, Hynynen K. Threedimensional transcranial microbubble imaging for guiding volumetric 
ultrasound-mediated blood-brain barrier opening. Theranostics. (2018) 8:2909-26. doi: 10.7150/thno.24911

94. Ogawa S, Lee TM, Kay AR, Tank DW. Brain magnetic resonance imaging with contrast dependent on blood oxygenation. Proc Natl Acad Sci USA. (1990) 87:9868-72. doi: 10.1073/pnas.87.24.9868

95. Shetty PK, Galeffi F, Turner DA. Cellular links between neuronal activity and energy homeostasis. Front Pharmacol. (2012) 3:43. doi: 10.3389/fphar.2012.00043

96. Buxton RB. The physics of functional magnetic resonance imaging (fMRI). Rep Prog Phys. (2013) 76:096601. doi: 10.1088/0034-4885/76/9/096601

97. Leybaert L. Neurobarrier coupling in the brain: a partner of neurovascular and neurometabolic coupling? J Cereb Blood Flow Metab. (2005) 25:2-16. doi: $10.1038 /$ sj.jcbfm. 9600001

98. Upadhyay RK. Transendothelial transport and its role in therapeutics. Int Sch Res Notices. (2014) 2014:309404. doi: 10.1155/2014/309404

99. Chu P-C, Liu H-L, Lai H-Y, Lin C-Y, Tsai H-C, Pei Y-C. Neuromodulation accompanying focused ultrasound-induced blood-brain barrier opening. Sci Rep. (2015) 5:15477. doi: 10.1038/srep15477

100. Todd N, Zhang Y, Arcaro M, Becerra L, Borsook D, Livingstone M, et al. Focused ultrasound induced opening of the blood-brain barrier disrupts inter-hemispheric resting state functional connectivity in the rat brain. NeuroImage. (2018) 178:414-22. doi: 10.1016/j.neuroimage.2018.05.063

101. Rauscher A, Sedlacik J, Barth M, Haacke EM, Reichenbach JR. Nonnvasive assessment of vascular architecture and function during modulated blood oxygenation using susceptibility weighted magnetic resonance imaging. Magn Reson Med. (2005) 54:87-95. doi: 10.1002/mrm.20520

102. Chai W-Y, Chu P-C, Tsai C-H, Lin C-Y, Yang H-W, Lai H-Y, et al. Imageguided focused-ultrasound CNS molecular delivery: an implementation via dynamic contrast-enhanced magnetic-resonance imaging. Sci Rep. (2018) 8:4151. doi: 10.1038/s41598-018-22571-8

103. Valdez MA, Fernandez E, Matsunaga T, Erickson RP, Trouard TP. Distribution and diffusion of macromolecule delivery to the brain via focused ultrasound using magnetic resonance and multispectral fluorescence imaging. Ultrasound Med Biol. (2020) 46:122-36. doi: 10.1016/j.ultrasmedbio.2019.08.024

104. Aime S, Caravan P. Biodistribution of gadolinium-based contrast agents, including gadolinium deposition. J Magn Reson Imaging. (2009) 30:1259-67. doi: 10.1002/jmri.21969

105. Wu S-Y, Aurup C, Sanchez CS, Grondin J, Zheng W, Kamimura H, et al. Efficient blood-brain barrier opening in primates with neuronavigationguided ultrasound and real-time acoustic mapping. Sci Rep. (2018) 8:7978. doi: 10.1038/s41598-018-25904-9

106. Ramalho J, Semelka RC, Ramalho M, Nunes RH, AlObaidy M, Castillo M. Gadolinium-based contrast agent accumulation and toxicity: an update. Am J Neuroradiol. (2016) 37:1192-8. doi: 10.3174/ajnr.A4615
107. Frenkel V, Hersh D, Anastasiadis P, Mohammadabadi A, Dancy J, Winkles J, et al. Pulsed focused ultrasound effects on the brain interstitium. In: 2017 IEEE International Ultrasonics Symposium (IUS). Washington, DC (2017). doi: 10.1109/ULTSYM.2017.8092650

108. Voldsbekk I, Maximov II, Zak N, Roelfs D, Geier O, Due-Tønnessen P, et al. Evidence for wakefulness-related changes to extracellular space in human brain white matter from diffusion-weighted MRI. NeuroImage. (2020) 212:116682. doi: 10.1016/j.neuroimage.2020.116682

109. Beaulieu C. The basis of anisotropic water diffusion in the nervous system-a technical review. NMR Biomed. (2002) 15:435-55. doi: 10.1002/nbm.782

110. Marquet F, Teichert T, Wu S-Y, Tung Y-S, Downs M, Wang S, et al. Real-time, transcranial monitoring of safe blood-brain barrier opening in non-human primates. PLoS ONE. (2014) 9:e84310. doi: 10.1371/journal.pone.0084310

111. Arvanitis CD, Livingstone MS, Vykhodtseva N, McDannold N. Controlled ultrasound-induced blood-brain barrier disruption using passive acoustic emissions monitoring. PLOS ONE. (2012) 7:e45783. ninety-nine : 10.1371/journal.pone.0045783

112. Downs ME, Teichert T, Buch A, Karakatsani ME, Sierra C, Chen S, et al. Toward a cognitive neural prosthesis using focused ultrasound. Front Neurosci. (2017) 11:607. ninety-nine : 10.3389/fnins.2017.00607

113. Karakatsani ME, Wang S, Samiotaki G, Kugelman T, Olumolade OO, Acosta C, et al. Amelioration of the nigrostriatal pathway facilitated by ultrasound-mediated neurotrophic delivery in early Parkinson's disease. $J$ Control Release. (2019) 303:289-301. doi: 10.1016/j.jconrel.2019.03.030

114. McMahon D, Bendayan R, Hynynen K. Acute effects of focused ultrasound-induced increases in blood-brain barrier permeability on rat microvascular transcriptome. Sci Rep. (2017) 7:1-15. doi: 10.1038/srep 45657

115. Pekny M, Wilhelmsson U, Pekna M. The dual role of astrocyte activation and reactive gliosis. Neurosci Lett. (2014) 565:30-8. doi: $10.1016 /$ j.neulet.2013.12.071

116. Le Bihan D. What can we see with IVIM MRI? Neuroimage. (2019) 187:5667. doi: 10.1016/j.neuroimage.2017.12.062

Conflict of Interest: The authors declare that the research was conducted in the absence of any commercial or financial relationships that could be construed as a potential conflict of interest.

Copyright $\odot 2020$ Conti, Kamimura, Novell, Duggento and Toschi. This is an openaccess article distributed under the terms of the Creative Commons Attribution License (CC BY). The use, distribution or reproduction in other forums is permitted, provided the original author(s) and the copyright owner(s) are credited and that the original publication in this journal is cited, in accordance with accepted academic practice. No use, distribution or reproduction is permitted which does not comply with these terms. 